\title{
Giacomo Casanova oder der Jacques le Fataliste der Liebe
}

Als der eigentliche Vater der französischen Encyclopédie darf der bereits mehrfach erwähnte Denis Diderot gelten, der von 1713 bis 1784 lebte und ebenfalls - wie so viele historische Figuren und „philosophes“ unserer Vorlesung - ein Jesuitenzögling war. Diderot verfasste im Verlauf der siebziger Jahre des 18. Jahrhunderts einen Roman, der aus heutiger Sicht eine Vielzahl insbesondere mentalitätsgeschichtlicher Entwicklungen vorwegnahm, die sich in jener Zeit anbahnten und die wir zu Beginn unserer Vorlesung bereits intensiv angesprochen hatten.

Dieser Text, der einige Elemente des ersten Romans der Moderne - Miguel de Cervantes' Don Quijote - in verfremdender Gestalt wieder aufnimmt, ist kein anderer als Jacques le fataliste et son maître. Es handelt sich um einen raffinierten Erzähltext, der von Reisestrukturen vollständig durchzogen ist. Er führt anhand dieser fundamental offenen Bewegungs-Strukturen aber vor allem Verstehens-Strukturen vor Augen und stellt es den Leserinnen und Lesern des Romans anheim, ihre eigenen Verstehens-Bewegungen anhand der Lektüre kritisch zu überprüfen. Noch heute ist es faszinierend, die radikale Modernität dieses Diderot'schen Erzähltexts zu überprüfen.

Die Koppelung zwischen beiden Strukturen - denen der Reisebewegungen und denen des Verstehens - wird uns bereits ab dem Incipit des Romans vor Augen geführt. Denn die Entfaltung der Narration gerät zu jedem Zeitpunkt zu einer kritischen Reflexion all jener Bewegungen, welche die Protagonisten des Romans, aber zugleich auch das Lesepublikum ausgeführt haben. In der berühmt gewordenen Eingangsszene, in welcher der Erzähler mit dem Leser ein fiktives Zwiegespräch über die Protagonisten des nachfolgenden Texts führt, treten die spezifischen Grundstrukturen der Reisebewegung im Roman und deren Koppelung oder Interaktion mit den Lesenden deutlich vor Augen. So heißt es in diesem experimentellen Text aus der Feder des französischen Philosophen:

Wie hatten sie sich getroffen? Durch Zufall, wie jedermann. Wie nannten sie sich? Was kümmert sie das? Woher kamen sie? Vom nächstgelegenen Ort. Wohin gingen sie? Weiß man denn, wohin man geht? Was sagten sie? Der Herr sagte nichts, und Jacques sagte, dass sein Capitaine sagte, dass alles, was uns hier unten an Gutem und an Schlechtem zustößt, dort oben geschrieben ward. ${ }^{1}$

1 Diderot, Denis: Jacques le fataliste et son maître. Edition critique par Simone Lecontre et Jean Le Galliot. Genf: Droz 1977, S. 3.

Ә Open Access. ( 2021 Ottmar Ette, publiziert von De Gruyter. (c) BY-NC-ND Dieses Werk ist lizenziert unter einer Creative Commons Namensnennung - Nicht-kommerziell - Keine Bearbeitung 4.0 International Lizenz. 
Dieser brillante Romanauftakt - ich gebe es gerne $\mathrm{zu}$ - fasziniert mich stets aufs Neue. Kann man mit weniger Worten einen Roman beginnen lassen, der notwendig seine Leserschaft und deren Reaktionen in das eigene Romangeschehen einbaut? Und einen moderneren zumal? denn in diesem Incipit ist der Schlüssel zum gesamten Erzähltext zu sehen; ein Schlüssel freilich, der nicht den Zugang zu einer klaren Bewegungsfigur eröffnet, sondern allem Tür und Tor öffnet, was sich bewegt. Denn von Beginn an werden alle möglichen Denk- und Bewegungsfiguren ganz bewusst eingeblendet und zugleich auch in ihrer vorgeblichen Vorbestimmtheit - im sehr eigentümlichen Fatalismus des Dieners Jacques - verankert. Und sein Herr und Meister schweigt, denn er hat nichts zu sagen! Mit Blick auf die historische Umbruchsituation der anstehenden Französischen Revolution ließe sich hinzufügen: Er hat nichts mehr zu sagen.

Am Anfang also steht ein Dialog der Erzähler- mit der Leserfigur. Doch die Erwartungsklischees der fiktiven Leserfigur werden ein ums andere Mal enttäuscht und ihre Fragen führen nur zu Gegenfragen: „Est-ce que l'on sait où l'on va?“ Die Fragen dieser Leserfigur treiben zugleich die Handlung voran. Und von welcher Kraft wird diese Handlung angeschoben? Der Zufall erscheint von Beginn an als eigentlicher Motor des Geschehens, und doch ist es, wie der allzu früh verstorbene Freiburger Romanist Erich Köhler in einer denkwürdigen Studie herausarbeiten konnte, ein Zufall, der im dialektischen Spiel mit der geschichtlichen Notwendigkeit ein in der jeweiligen historischen Situation angelegtes Mögliches entbindet und entfaltet. ${ }^{2}$ Die herausragende Rolle des Zufalls ist es, die das narrative Spiel in Gang setzt und hält - und fast fühlt man sich an Honoré de Balzac erinnert, der nur wenige Jahrzehnte später im Vorwort zu seiner Comédie humaine seiner Leserschaft erklärte, dass der Zufall „le plus grand romancier du monde“ sei. Doch darauf will ich nicht zurückkommen, dies hatten wir ausführlich in unserer Vorlesung zum 19. Jahrhundert und zur Romantik zwischen zwei Welten besprochen.

Dem Geschehen in Diderots Jacques le fataliste liegt ebenso wenig ein göttlicher Heilsplan zugrunde wie der Reise ein detaillierter oder auch nur (voraus-) bestimmbarer Fahrplan. Alles ist von einem Augenblick auf den anderen veränderbar, ja verwirrbar; Herkunft und Zielort entziehen sich der Kenntnis der Leserschaft. Ein genau bestimmbarer Ort der Ankunft wird durch die Betonung

2 Vgl. Köhler, Erich: Der literarische Zufall, das Mögliche und die Notwendigkeit. München: Fink 1973, sowie (ders.): „Est-ce que l’on sait où l’on va?“ - Zur strukturellen Einheit von „Jacques le Fataliste et son Maître“. In (ders.): Vermittlungen. Romanistische Beiträge zu einer historisch-soziologischen Literaturwissenschaft. München: Fink 1976, S. 219-239. 
einer radikalen Offenheit der Zukunft und des weiteren Reisewegs ersetzt: Weiß man denn, wohin die Reise geht?

Ich möchte an dieser Stelle unsere Lektüre von Diderots narrativem Kleinod seinem erzählerischen „bijou“ - abbrechen, um zu einem Werk zu kommen, das in vielerlei Hinsicht diese narrative Modellform in einem vielbändigen Erzählwerk umzusetzen scheint. Und doch ist dieses vielbändige Werk nichts anderes als die Lebensgeschichte eines Menschen, den der Zufall in die unterschiedlichsten Länder Europas verschlagen hat - im Übrigen auch, wie wir gleich sehen werden, nach Berlin, nach Potsdam und nach Sanssouci. Es handelt sich um die Lebensgeschichte eines Italieners, dessen Namen Sie ganz ohne Zweifel kennen und den ich Ihnen nicht zu buchstabieren brauche: die Memoiren von Giacomo Casanova.

Vor diesem Hintergrund ist es nur folgerichtig, dass Casanovas Histoire de ma vie im Grunde eher zufällig und kurz nach einer letzten Begegnung mit der schönen Irene beziehungsweise ihrer Tochter abbricht, als der Schriftsteller und Darsteller seines Lebens am 3. September 1774 das berühmte Begnadigungsschreiben der Inquisition erhielt, das ihm die Rückkehr nach Venedig erlaubte. Damit waren die Reisewege des Giacomo Casanova noch lange nicht erschöpft, wohl aber die literarischen Bewegungen, deren nicht enden wollende Parcours ich Ihnen gerne anhand der letzten Passage vor dem Abbrechen der Geschichte meines Lebens ${ }^{3}$ gerne vorführen möchte. Lauschen Sie also bitte dem Ende dieser Memoiren:

\begin{abstract}
Sie erschien einige Tage später mit ihrer Tochter, die mir gefiel und mir kleine Liebkosungen nicht verweigerte. Eines schönen Morgens traf sie den Baron Pittoni, der die kleinen Mädchen ebenso liebte wie ich, an Irenes Tochter Geschmack fand und die Mutter bat, ihm gelegentlich die gleiche Ehre zu erweisen wie mir. Ich ermutigte sie, dieses Angebot anzunehmen, und der Baron verliebte sich in das Mädchen. Das war ein Glück für Irene, denn gegen Ende des Karnevals wurde sie angezeigt. Wäre der Baron nicht ihr Freund geworden, hätte er die Strenge der Polizeivorschriften walten lassen; so aber warnte er sie rechtzeitig, mit dem Spielen aufzuhören. Man konnte sie zu keiner Geldstrafe verurteilen, weil man, als man überraschend bei ihr erschien, keine Gäste vorfand.

Zu Beginn der Fastenzeit reiste sie mit der ganzen Truppe ab; drei Jahre später traf ich sie in Padua, wo ich mit ihrer Tochter eine weit zärtlichere Bekanntschaft schloss. ${ }^{4}$
\end{abstract}

Es hätte kaum ein schöneres Ende dieser literarischen Lebensgeschichte geben können als dieses unvermittelte Ende, das die eine Liebesgeschichte abschließt,

3 Casanova Chevalier de Seingalt, Giacomo: Geschichte meines Lebens. Mit einem Essay von Peter Quenell. Herausgegeben und eingeleitet von Sauter. XII Bände. Berlin: PropyläenVerlag 1985.

4 Ebda., Bd. 12, S. 255 f. 
um nach einem Sprung in Raum und Zeit eine weitere Liebesgeschichte zu beginnen, die sich vielversprechend anlässt, um sodann kommentar- und wortlos abzubrechen. Die Liebe zur Mutter öffnet sich auf die Liebe zur Tochter, wobei sich zwischen beide viele andere Liebesgeschichten einreihen, die der venezianische Autor freilich nicht mehr zu erzählen vermag.

Was hätte es verändert, wenn Casanova uns auch noch diese Liebesgeschichten und die damit verbundenen Reisebewegungen erzählt beziehungsweise dem Papier seiner Memoiren anvertraut hätte? Er hätte auch nach seiner Rückkehr nach Venedig und dem kurzen Aufenthalt in seiner Vaterstadt schon bald nicht mehr sagen können, wie sich seine Lebensgeschichte als Lebensreise weiter entspinnen würde. Denn stets nahm er in eben jenem aktiven Fatalismus - wie er für Diderots Jacques le fataliste so charakteristisch ist - die Dinge wahr, die auf ihn zukamen, und erfreute sich der nächsten Gelegenheit zu einer liebevollen Bekanntschaft, die „da oben geschrieben“ ward, um mit den Worten von Jacques' Hauptmann zu sprechen.

Beschäftigen wir uns also mit einem literarischen Autor, mit dem ich mich bereits in meiner Vorlesung über Reiseliteratur auseinandergesetzt habe, ${ }^{5}$ einem Schriftsteller, der freilich nicht für das Verfassen von Reiseliteratur berühmt geworden ist. Wir befinden uns in der zweiten Hälfte des 18. Jahrhunderts und daher mitten in der zweiten Phase beschleunigter Globalisierung. Ich möchte Ihnen auf der vorletzten Strecke dieser Vorlesung über die Aufklärung zwischen zwei Welten einen Autor vorstellen, der eher für die literarische Darstellung der Sitten seiner Zeit und insbesondere die Formen intimen Lebens stehen kann, die er wie kaum ein anderer Schriftsteller uns nahezubringen verstand. Doch will ich unsere Vorlesung über das Aufklärungszeitalter nicht abschließen, ohne auf den Bereich dieses intimen Lebens zu kommen, den auch ein Fray Servando Teresa de Mier wiederholt darstellte. Er tat dies freilich aus der Position eines Dominikanermönches und ,Outsiders‘, während Casanova eine gesellschaftliche Außenposition besaß, die es ihm erlaubte, ebenso die Lebensnormen wie die Lebensformen der „vie intime“ des 18. Jahrhunderts sehr detailreich und von innen zu porträtieren.

Dabei ist zum einen das vielbewegte Leben Giacomo Casanovas, der sich den Ehrentitel eines Chevalier de Seingalt recht selbstbewusst erwählte und den „sein galant“, den galanten Busen dabei bestimmt auch im zwinkernden Auge hatte, nicht von vielfältigsten Reisen zu trennen, die ihn an verschiedene

5 Vgl. das Casanova gewidmete Kapitel im Auftaktband der Reihe „Aula“ in Ette, Ottmar: ReiseSchreiben, S. 341-367. 


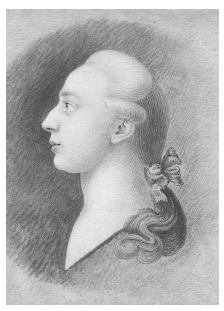

Abb. 41: Francesco Casanova: Porträt seines Bruders Giacomo Girolamo Casanova (1725-1798).

Enden des damaligen Europa führte. Wir erhalten folglich nicht nur ein Sittengemälde von Venedig oder dem Veneto, sondern im Grunde von ganz Europa über einen Zeitraum, welcher die Jahrzehnte größter philosophischer Aktivitäten umfasst. Und unser Autor war über all diese Entwicklungen bestens informiert, wie wir bereits gesehen hatten, als wir Giacomo Casanova zu einem Besuch bei Jean-Jacques Rousseau begleiteten.

Casanova war im vollsten Sinne ein Kind seiner Zeit und daher befugt, ja prädestiniert dafür, uns dieses Zeitalter in allen intimen wie gesellschaftlichen Aspekten vorzustellen. Er liebte die erlesene Gesellschaft und kostete ihren weiblichen Charme aus, bis er jeweils an andere Orte fliehen musste, um sich selbst vor Verfolgungen zu schützen und andererseits seine amourösen Abenteuer weiterführen zu können. Zum anderen aber lebte und liebte er nicht nur dieses Leben, sondern schrieb es auch im avancierten Alter nieder, wurde also zum Verfasser der Histoire de ma vie, mit der er seine Laufbahn schriftstellerisch krönte und zu einem gelungenen Abschluss führte.

So ging der Venezianer ein in jene ,Hall of Fame' der Liebenden, die der Liebe und dem Gott Amor, aber nicht der Geliebten opfern - und zugleich in jene der Reisenden, hatte er gegen Ende seines Lebens doch einen guten Überblick über die Fürstenhöfe, die sich über fast ganz Europa verstreuten, sowie über die unterschiedlichsten Landschaften, die er auf seinen Fahrten und Fluchten durchquerte. Casanova war ein Europäer im vollen Wortsinne und ähnlich europäisch-kosmopolitisch geprägt wie sein Zeitgenosse José Cadalso, der schon in früher Kindheit eine vorzügliche Bildung genoss. Casanova hingegen verschaffte sich diese Bildung eher autodidaktisch und bildete sich ständig durch viele menschliche Kontakte in wechselnden kulturellen und sprachlichen Kontexten weiter. Es kann kein Zweifel daran bestehen: Giacomo Casanova ist sicherlich eine der faszinierendsten Figuren des großen Zeitalters der Aufklärung. Auch wenn er kein umfassendes philosophisches System geschaffen hat, hinterließ er doch eines der aufschlussreichsten Werke, um das Zeitalter der Aufklärung in Europa sinnlich zu begreifen - und dies vor allem im Bereich des europäischen Adels, aber auch mit Einblicken in das Leben von 
Bauernmädchen oder bürgerlichen Frauen, von aristokratischen Salondamen bis zu ihren philosophischen Gästen.

Denn Giacomo Casanova bewegt sich in seinen literarischen Texten stets innerhalb eines Vektorenfeldes des Begehrens. Seine unsteten, sprunghaften Reisebewegungen beruhen immer auch auf einem Begehren des Anderen - anderer Landschaften, anderer Reichtümer, anderer Erfahrungen und anderer Menschen. Seine Neugier ist ebenso unersättlich wie seine Liebessehnsucht. In der Bewegung des Reisens und des oder der Reisenden verknüpfen sich Motion und Emotion, verbinden sich also die physisch-topographische Bewegung mit der inneren Gefühlsbewegung, wobei diese emotionale Seite des Reisens nicht als sekundär bewertet werden sollte. Denn das Begehren ist eine mächtige Antriebskraft in der affektiven Ökonomie des Menschen. ${ }^{6}$ In Giacomo Casanova verkörpern sich die emotionalen Beweg-Gründe von Mobilität.

Andererseits hat eben dieses Begehren und seine Ökonomie auch sehr viel damit zu tun, dass das Reisen nicht selten auch mit dem Sammeln einhergeht. ${ }^{7}$ Wir sammeln bei unseren Reisen Erfahrungen und Erlebnisse, bisweilen aber auch Reiselektüren, die sich für uns in Gemeinschaft mit bestimmten Landschaften einprägen. Vor allem aber sammeln wir Kontakte mit anderen Menschen, wobei dies bei Casanova sicherlich im Bereich intimer zwischenmenschlicher Beziehungen ganz zweifellos der Fall war. Giacomo Casanova kann aus der Sicht dieser affektiven Ökonomie ${ }^{8}$ folglich als ein passionierter Sammler bezeichnet werden. Dabei war seine Sammelleidenschaft unbegrenzt, so wie es auch das abrupte Ende seines vielbändigen Lebenswerkes der Geschichte meines Lebens exemplarisch vor Augen führt.

Vor diesem Hintergrund sollten wir uns mit ein paar Stationen im Leben des Giacomo Casanova beschäftigen, um auf diese Weise einen Überblick über einige biographische Facetten seines autobiographischen Leben-Schreibens zu erhalten. Vorausgeschickt sei, dass es dem Lebenslauf des Venezianers wahrlich nicht an Bewegung fehlte; und doch war dies zugleich repräsentativ für die Blütezeit des europäischen 18. Jahrhunderts und eine gewisse gesellschaftliche Elite, welche von einem hohen Grad an Internationalisierung sowie an internationalem Austausch geprägt war, wie wir ihn vielleicht erst in unserer aktuellen

\footnotetext{
6 Vgl. zu diesem Komplex Hindemith, Gesine / Stöferle, Dagmar (Hg.): Der Affekt der Ökonomie. Spekulatives Erzählen in der Moderne. Berlin - Boston: Walter de Gruyter 2018; sowie Bidwell-Steiner, Marlen: Das Grenzwesen Mensch. Vormoderne Naturphilosophie und Literatur im Dialog mit postmoderner Gendertheorie. Belin - Boston: Walter de Gruyter 2017.

7 Vgl. Sánchez, Yvette: Coleccionismo y literatura. Madrid: Ediciones Cátedra 1999.

8 Vgl. hierzu Schlünder, Susanne / Stahl, Andrea (Hg.): Affektökonomien. Konzepte und Kodierungen im 18. und 19. Jahrhundert. Paderborn: Wilhelm Fink 2018.
} 


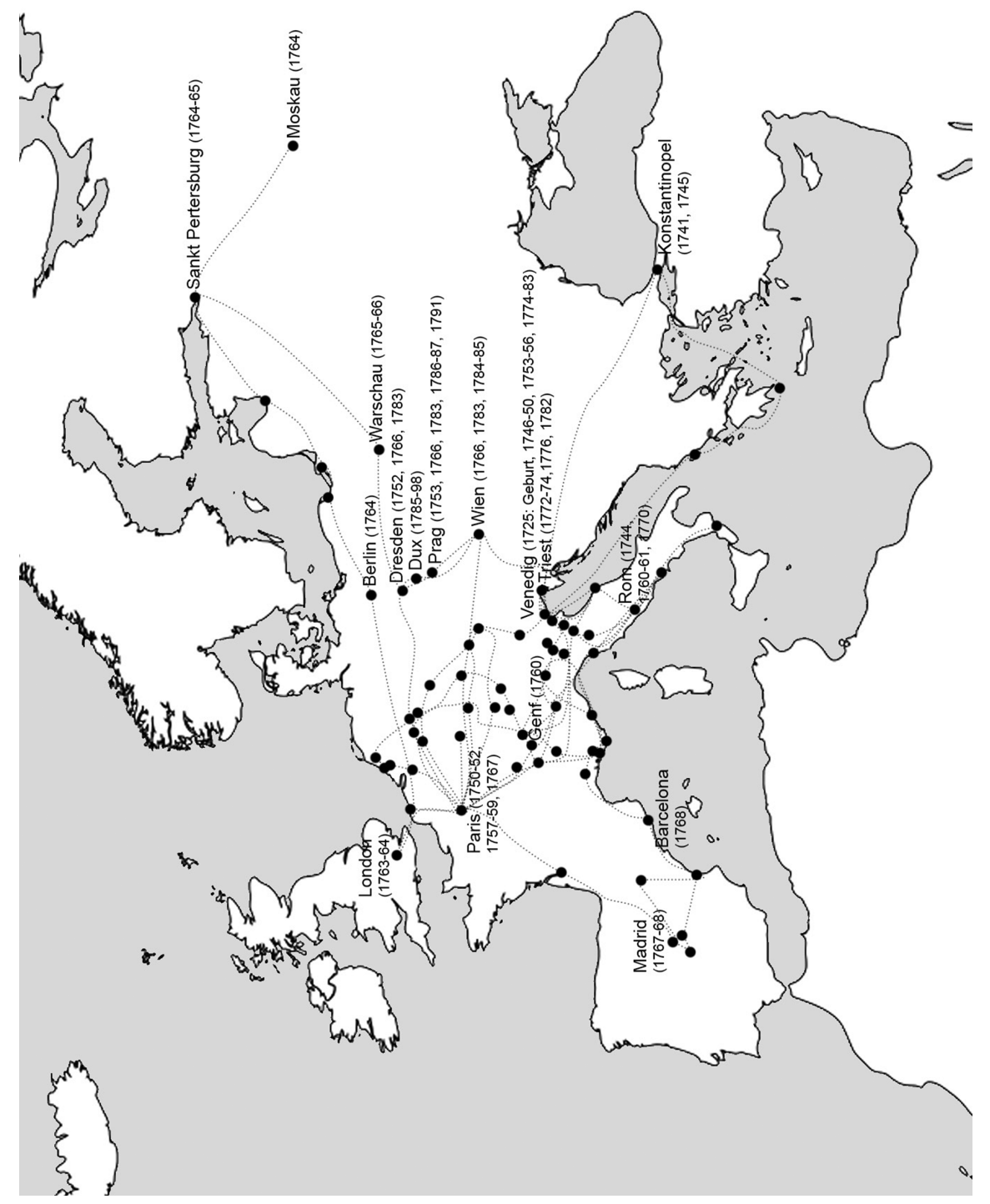

Abb. 42: Casanovas wichtigste Reisestationen in Europa. 
Epoche wieder erreicht haben. Mit Casanova befinden wir uns ganz selbstverständlich innerhalb der République des Lettres des europäischen Aufklärungszeitalters. Mag diese Elite auch zahlenmäßig begrenzt gewesen sein: Sie war national wie international zumeist bestens vernetzt.

Giacomo Girolamo Casanova wurde am 2. April 1725 in Venedig als Sohn des Gaetano Casanova und seiner Frau Zanetta geboren. Nichts deutete auf den späteren Lebensweg des Venezianers hin, der nicht von adeliger Abkunft war. Seine Eltern waren beide Schauspieler - eine für das künftige Leben des jungen Mannes nicht ganz unbedeutende Tatsache. Denn bühnenreife Inszenierungen gab es im Leben Casanovas zuhauf. Die Lagunenstadt - so ließe sich sagen war seine Heimat und blieb trotz aller Fluchten, Reisen und Verbannungen im Grunde der Mittelpunkt seines gesamten Lebens, auch wenn sie dem für lange Zeiten aus seiner Vaterstadt Verbannten und von der Inquisition Verfolgten bisweilen wie ein ferner, unerreichbarer Traum erschien. Nach Venedig trieb es ihn von allen ,Ausflügen“ und Exkursionen - so weit weg sie ihn auch immer führen mochten - stets wieder zurück. Es verbitterte ihn im Alter sehr, noch ein letztes und endgültiges Mal aus der Stadt mit ihren Kanälen und den vielen mysteriösen Palästen verbannt worden zu sein. Aber Casanova war auch fernab der Stadt stets stolzer Venezianer.

Als neunjähriger Junge kam Giacomo - sein Vater verstarb bereits, als er acht Jahre alt war - in ein Internat ins nahe gelegene Padua, ${ }^{9}$ wo wir Casanova bereits am Ende seiner Lebensgeschichte gesehen hatten. Er erwies sich rasch als außergewöhnlich begabt und eignete sich schnell immer neues Wissen an, so dass er bereits 1737 an der altehrwürdigen Universität von Padua immatrikuliert wurde. Nach fünfährigem Studium erwarb er dort den Grad eines Doktors der Rechte, auch wenn wir nicht moderne mitteleuropäische Maßstäbe an das damalige Bildungssystem anlegen sollten. Im Zentrum seiner Studien wie auch der seiner Kommilitonen stand die Lehre von den Sieben Freien Künsten, wobei als Grundstudium die Fächer Grammatik, Rhetorik und Dialektik gelehrt wurden. Der junge Casanova absolvierte alles mit Bravour und qualifizierte sich damit für höhere Aufgaben.

Es war keineswegs ungewöhnlich, dass Casanova bereits als Siebzehnjähriger sein Studium mit dem Doktortitel, als Doktor beider Rechte (des weltlichen wie des kanonischen Rechtes) abschließen konnte. Seine Mutter wie seine Großmutter wollten die Zukunft des jungen Mannes als Rechtsgelehrter im Dienste der Katholischen Kirche sichern; daher erhielt er 1740 die Tonsur und

9 Vgl. zur Biographie u. a. Loos, Erich: Einleitung. In: Casanova Chevalier de Seingalt, Giacomo: Geschichte meines Lebens, Bd. 1, S. 37-60. 
1741 die niederen Weihen: Aus dem Studenten wurde der Abate Casanova und damit einer jener unzähligen „Abbés“, die das Aufklärungszeitalter auf beiden Seiten des Atlantiks bevölkerten. Den jungen und talentierten Kleriker empfahl die rührige Mutter zunächst einem Bischof in Kalabrien: Casanova reiste 1743 nach Martirano in der Nähe des schönen Cosenza, was den Beginn eines durchaus abenteuerlichen Wanderlebens markierte. Denn das bescheidene Bergstädtchen in Kalabrien vermochte ihn nicht zu halten - Casanova hatte andere Pläne.

Über Neapel reiste er nach Rom, wo er als Sekretär des spanischen Gesandten Kardinal Aquaviva eine sichere Laufbahn hätte beginnen können. Alle Türen standen ihm offen, ein gesellschaftlicher Aufstieg erwartete ihn. Er verfügte zudem über beste Beziehungen zum Papst, der ihn zum „apostolischen Protonotar“ ernannte sowie zum Ritter des Goldenen Sporns, was ihm die Führung des Titels eines Chevalier ermöglichte. Alles hätte so gut in seinem Leben laufen können, wenn nicht eine amouröse Entführungsgeschichte seinen weiteren Aufstieg unterbrochen hätte. Der junge Mann musste Rom fluchtartig verlassen und seine vom Zufall diktierte Bewegungsfigur hatte begonnen.

Giacomo Casanova gelangte nach Bologna, wo er sich 1744 entschloss, das geistliche Gewand abzulegen und sein Glück - ganz im Sinne von Stendhals Le rouge et le noir - nunmehr als Soldat zu versuchen. Doch anders als José Cadalso war er zum Soldaten und Offizier nicht geboren: Bereits 1745 verzichtete er nach Erfahrungen im Dienste der Republik Venedig auf der Insel Korfu und wohl auch in Konstantinopel auf eine Fortsetzung seiner eher tristen und bescheidenen Soldatenlaufbahn. Er träumte von höheren Aufgaben, für die er sich empfehlen wollte und für die er noch nach passenden Gelegenheiten suchte.

Eine solche präsentierte sich schon bald: Casanova lebte zunächst in Venedig vom Geigenspiele und hatte zudem das Glück, den Senator Bragadin von einer Art Schlaganfall zu heilen. Dieser glaubte darauf im geschickten Casanova einen Vermittler zum Überirdischen gefunden $\mathrm{zu}$ haben und behandelte ihn wie einen Sohn, so dass ihm nun wieder alle Mittel für ein gutes Leben zur Verfügung standen. Es ist auffällig, wie häufig sich das Glück und die Möglichkeit zu einem ,normalen“ Lebenslauf in Casanovas Karriere eröffneten. Doch auch diese Türen schlug der junge Mann wieder entschlossen zu: Zwischen 1746 und 1749 scheint er alle in ihm schlummernden Fähigkeiten als Spieler und Verführer vervollkommnet zu haben. Sein Lebenswandel wurde der venezianischen Inquisition verdächtig, so dass er 1749 Venedig verließ, mehrere oberitalienische Städte besuchte und schließlich ins französische Lyon reiste, wo der ehemalige venezianische Abbé Freimaurer wurde. Das Schicksal hatte es mit Casanova anders gemeint: Casanova ließ sich von allerlei sich ihm bie- 
tenden Zufällen treiben. Mit einer Art aktivem Fatalismus ergriff er jede Gelegenheit beim Schopfe, die sich ihm bot: nicht nur in Sachen Liebe.

Schon 1750 finden wir ihn erstmals in Paris, wo es ihm nicht schwerfiel, bald Zugang zu den vornehmsten Zirkeln zu finden. 1752 ging er dann nach Dresden, um am dortigen Hofe seine als Schauspielerin tätige Mutter zu besuchen. Für deren Theatergruppe schrieb Casanova die italienische Fassung einer französischen Oper sowie eine Parodie auf eine Tragödie von Racine: Casanova war mit der europäischen Literatur bestens vertraut. Beide Werke wurden mit Erfolg aufgeführt. Hätte der Sohn von Schauspielern das Zeug zu einem berühmten Bühnenautor gehabt?

Vom damaligen Elbflorenz begab er sich weiter nach Wien und schließlich wieder nach Venedig, wo er nach zwei Jahren müßiggängerischer Abenteuer am 26. Juli 1755 wegen Beschäftigung mit den Geheimwissenschaften, Beleidigung der Religion sowie wegen seiner Tätigkeit als Freimaurer verhaftet und unter den berüchtigten Bleidächern des Dogenpalastes eingekerkert wurde den sogenannten ,Bleikammern'. Doch gerade dieses berühmte Gefängnis, aus dem es wohl niemals gelungene Ausbruchsversuche gegeben hatte, bildete für sein waches Denken eine Herausforderung: Wie ein italienischer Fray Servando Teresa de Mier plante er minutiös seine Flucht.

Und sein Plan gelang: Am 31. Oktober 1756 glückte ihm sein sensationeller Ausbruchsversuch, der überall in Europa Aufsehen erregte. Casanova hatte seinen sprichwörtlichen Lebenswillen und Überlebenswillen, aber auch seine Intelligenz tatkräftig unter Beweis gestellt. Auch wenn sein Buch über diesen seinen Ausbruchversuch erst sehr viel später, im Jahre 1788, erscheinen sollte: Die europäische Öffentlichkeit wurde auf den Venezianer aufmerksam.

Casanova beschloss, wieder nach Paris zu reisen, wo der aufgrund seiner spektakulären Flucht berühmt Gewordene durch sein außerordentliches Organisationstalent als Mitbegründer der Königlichen Lotterie und durch das Vertrauen der Marquise d'Urfé zu einem reichen Mann wurde. So war die Lotterie für ihn ebenfalls ein wichtiges Sprungbrett, auch wenn es ihm nicht wie La Condamine im Verbund mit Voltaire gelang, sie mathematisch zu knacken. Wieder einmal schien Casanova in einer beneidenswerten Stellung zu sein, die ihm alle Chancen für ein glückliches und ruhiges Leben eröffnete.

Und wieder einmal kam alles anders! Denn auch diesmal schlug Casanova diese Chance aus und genoss seine Stellung in vollen Zügen, wobei er erneut seine Spielernatur bewies. Durch seine Aktivitäten geriet er bald wieder in Verdacht, so dass er es vorzog, Ende 1759 die französische Hauptstadt mit unbekanntem Ziel zu verlassen. Ein unstetes Nomadenleben zwischen verschiedensten europäischen Städten schloss sich an: Giacomo Casanova wird auf seinen Reisen durch Frankreich, Deutschland, die Schweiz oder die Niederlande für seine viel- 
fältigen Liebschaften berühmt und berüchtigt. Es ist der Casanova, welcher nicht mehr als illustrer Ausbrecher, sondern als unersättlicher Liebhaber geradezu sprichwörtlich in die europäische Sittengeschichte einging.

Diese bewegte Phase endete mit einem Aufenthalt in London von Juni 1763 bis März 1764. Bei Casanova verstärkte sich zwischenzeitlich freilich das Bewusstsein, den Höhepunkt seines vielbewegten Lebens bereits überschritten zu haben. Sein Weg führte den Venezianer auch zu Friedrich den Großen an den preußischen Hof zu Potsdam und Berlin; doch das Angebot Friedrichs, Erzieher an der Kadettenakademie der preußischen Armee zu werden, lehnte Casanova schließlich ab. Es hätte einem ja Angst und Bange um die jungen Kadetten des Preußenkönigs und um den möglichen Sittenverfall in Preußen werden können, hätte Casanova dieses erzieherische Amt übernommen ... War Friedrich der Große doch nicht ganz auf der Höhe seiner Zeit, zumindest was die europäische Gerüchteküche anging? Oder war Casanovas Ruf doch nicht so weit nach Osten gedrungen? Sei es, wie es wolle, Casanova versucht nun sein Glück vergeblich am Hofe der Zarin Katharina II von Russland. Obwohl sich der Venezianer neun Monate in St. Petersburg und am dortigen Hof aufhält, kann oder will ihm die Zarin doch keine adäquate Stellung bieten: Wusste sie mehr als der - anders als sie - in Liebesdingen nicht sehr erfahrene Preußenkönig? Casanova jedenfalls orientiert sich wieder neu.

Seine nächste Station ist Warschau, wo er das Duell um Liebeshändel mit dem polnischen Kronkämmerer Graf Branicki wie dieser schwerverletzt übersteht, so dass er im Sommer 1766 fluchtartig Polen wieder verlassen muss und nach Wien weiterzieht. Dort war man besser unterrichtet als in Preußen. In Wien gerät er bald mit der sogenannten ,Keuschheitskommission“ in Konflikt und wird des Landes verwiesen. Ein erneuter kurzer Aufenthalt in Paris endet wiederum mit der Ausweisung im November 1767, wonach er sich nach Spanien wendet, dessen rigoroses gesellschaftliches Klima ihm aber missfällt. In Madrid wird er bald wegen unerlaubten Waffenbesitzes kurzzeitig eingekerkert. Auf der Iberischen Halbinsel pendelt sein Leben weiterhin zwischen Gefängnis und Bett: Liebeshändel bringen ihm in Barcelona 1768 eine Kerkerhaft von zweiundvierzig Tagen ein, die er unter anderem zur Niederschrift einer umfangreichen Verteidigung der venezianischen Politik gegen französische Historiographen nutzt. Casanova dachte an seine geliebte Lagunenstadt und sehnte sich nach ihr. Er versuchte alles, um die venezianische Obrigkeit wie die heilige Inquisition günstig für seine Gnadengesuche zu stimmen.

Das angesprochene Werk über Venedig erschien 1769 unter falscher Verlagsangabe in Lugano, wobei diese Veröffentlichung ihm die Gunst der venezianischen Regierung gewinnen und die Rückkehr in die Heimatstadt ermöglichen sollte. In der Folge verfasste Casanova eine Fülle literarischer Arbeiten, die sich 
mit verschiedensten, auch naturwissenschaftlichen Themen befassen. Er hält sich in der Nähe des Territoriums der Republik Venedig auf, um dem von ihm ersehnten Ruf der Serenissima sofort folgen zu können; doch dieser lässt auf sich warten. So arbeitet er 1771 in Florenz an einer Übersetzung der Ilias, von der mehrere Teile erscheinen, und lebt dann von 1772 bis 1774 - mit einer großen historiographischen Arbeit über Polen beschäftigt - unter anderem in Triest.

Casanova hält sich vorwiegend in Italien auf, um im Begnadigungsfalle schnellstmöglich nach Venedig eilen zu können. Dabei entstehen unvermeidlich zahlreiche Liebschaften in unterschiedlichen italienischen Landschaften; doch gewährt uns der Venezianer auch tiefe Einblicke in das Leben einer internationalen Elite im Zeitalter der europäischen Aufklärung. Man beschäftigte sich viel mit Spielen um Liebe und Geld, aber auch mit mancherlei Naturwundern und Kuriositäten, die man sich gerne zum Ziele eines gemeinsamen unterhaltsamen Nachdenkens vorführte. Ich möchte Ihnen gerne eine dieser Szenen aus der Geschichte meines Lebens zeigen, bei der wir eine italienische Herzogin mit ihren internationalen Gästen betrachten können:

Nach dem Souper spielte sie mit den beiden Engländern und den beiden Sachsen eine Parti Quinze; die Einsätze waren klein, die Verluste mittelmäßig, die Sachsen gewannen. Ich entschloß mich, ein anderes Mal mitzuspielen. Am nächsten Tag gingen wir alle zum Mittagessen zum Prinzen von Francavilla, der uns ein prächtiges Mahl auftischte und uns gegen Abend zu einem kleinen Badebecken führte, das er am Strand besaß; dort zeigte er uns ein Naturwunder. Ein Priester sprang ganz nackt ins Wasser, schwamm und ruhte sich von Zeit zu Zeit aus, ohne deshalb unterzugehen. Er verwandte dazu keinen Kunstgriff. Uns blieb nur der Schluß übrig, daß es nur durch den inneren Bau seines Organismus zu erklären war. Nachher führte der Prinz Milady ein höchst anziehendes Schauspiel vor. Er ließ vor ihr reizende halbwüchsige Burschen ganz nackt im Wasser schwimmen; sie alle waren Lustknaben des liebenswürdigen Prinzen, der seiner Veranlagung nach das männliche Geschlecht dem weiblichen vorzog. Die Engländer fragten ihn, ob er ihnen das gleiche Schauspiel mit Mädchen bieten wolle; er versprach es ihnen für den nächsten Tag in seinem Teich im Garten eines Hauses, das er in der Nähe von Portici besaß. ${ }^{10}$

Wir erleben eine internationale Gesellschaft beim Spiele und bei unterschiedlichen Lustbarkeiten auf dem adeligen Anwesen. Giacomo Casanova berichtet ganz selbstverständlich ebenso von homosexuellen Liebesspielen mit Lustknaben wie von heterosexuellen Amüsements, die in diesem Falle für die Engländer mit gewiss minderjährigen italienischen Mädchen vorbereitet werden. All dies wäre in den bürgerlichen europäischen Gesellschaften des 19., des 20. und des 21. Jahrhunderts Straftatbestände gewesen, wobei der Umgang mit zweifel-

10 Casanova, Giacomo: Geschichte meines Lebens, Bd. 11, S. 316. 
los ebenfalls minderjährigen Lustknaben sowohl wegen des Missbrauchs Minderjähriger als auch wegen homosexueller Beziehungen verfolgt worden wäre. Lediglich die Homosexualität wurde in verschiedenen Ländern Europas im Verlauf der zweiten Hälfte des 20. oder zu Beginn des 21. Jahrhunderts entkriminalisiert, selbst wenn sie in manchen auch europäischen Ländern noch immer unter Strafe steht und als Verbrechen behandelt wird. Ich möchte Ihnen mit dieser kurzen Szene nicht ein Modell sexueller Freizügigkeit vor Augen führen oder gar den sexuellen Missbrauch von Minderjährigen ,normalisieren', sondern Ihnen bewusst machen, mit welcher Selbstverständlichkeit die internationale Adelsgesellschaft des 18. Jahrhunderts mit unterschiedlichsten Formen von Sexualität umging. Ich bitte Sie, dies in Erinnerung zu behalten, wenn wir uns ein wenig später in der gebotenen Kürze mit dem Marquis de Sade beschäftigen werden.

Doch zurück zu den gleichzeitigen Unternehmungen und Plänen Casanovas, wieder in sein Venedig zurückkehren zu dürfen! Durch unterschiedliche Agentendienste suchte er die Gunst der venezianischen Inquisition für sich zu gewinnen und die dortige Regierung für sich einzunehmen. Lange muss sich der gebürtige Venezianer gedulden, doch erfüllen sich seine Hoffnungen endlich im November 1774, als ihm die ersehnte Begnadigung zuteilwird: Giacomo Casanova darf an einem 14. September des Jahres 1774 in sein so sehnlich vermisstes Venedig zurückkehren.

In seiner Geburtsstadt lebt er zunächst zurückgezogen; er arbeitet unter anderem als Spitzel für die venezianische Staatsinquisition und verschafft sich damit einen scheinbar sicheren Status. Seine spitzelberichte unterzeichnet er, wenn man der Forschungsliteratur glauben darf, mit dem Pseudonym Antonio Pratolini. ${ }^{11}$ Doch es gibt keine Kontinuität im Leben des Giacomo Casanova außer der, ständig in Bewegung oder auf der Flucht zu sein - und es ist überaus spannend, die Parallelen zu unserem neuspanischen Dominikanermönch Fray Servando Teresa de Mier auszuleuchten. 1782 verfasst er nach dem Wortwechsel mit einem Patrizier eine scharfe Satire, was ihm die abermalige und endgültige Verbannung aus Venedig einträgt. Sein Wanderleben setzt wieder ein, das ihn für kurze Zeit nach Paris und schließlich nach Wien führt, wo er 1784 Sekretär des venezianischen Gesandten Foscarini wird - doch auch diese Position wird nicht von Dauer sein.

Nach Foscarinis Tod bietet ihm der junge Graf von Waldstein die Stelle eines Bibliothekars in seinem Schloss im nordböhmischen Dux an: Im September 1785

11 Vgl. Bolitho, William: Zwölf gegen das Schicksal - Die Geschichte des Abenteuers. Traunstein: Müller und Kiepenheuer 1946, S. 78. 
übernimmt Casanova sein neues Amt, unterhält eine weitläufige Korrespondenz mit zahlreichen europäischen Persönlichkeiten, widmet sich wissenschaftlichen und literarischen Arbeiten und beginnt um 1790 mit der Niederschrift seiner Memoiren. Diese umspannen insgesamt die Jahre zwischen 1733 und 1774, mithin vier bedeutsame Jahrzehnte jener Epoche der Aufklärung, die Giacomo Casanova in seiner in französischer Sprache verfassten Histoire de ma vie als ein herausragender Zeitzeuge für uns kommentiert und uns nahebringt. Ein Leben, das sich wie ein Reisebericht liest, kommt zu seinem intensiven schriftstellerischen Ende.

Denn nach einer schwierigen Veröffentlichungs- und Übersetzungsgeschichte wird es dieses Bild sein, das von Giacomo Casanova bleibt: das des venezianischen Schriftstellers, der in der Sprache der République des Lettres schreibt und Europäer durch und durch ist. Erst vor wenigen Jahren hat die Bibliothèque de France die Manuskripte von Casanovas Histoire de ma vie für einen nicht ganz zweistelligen Millionenbetrag erworben, der meines Wissens nur noch durch die zwölf Millionen für den Ankauf der Reisetagebücher Alexander von Humboldts überboten wurde. Auch diese Tatsache mag belegen, dass Casanova längst aus der etwas verruchten Ecke herausgekommen und zu einem der großen in französischer Sprache schreibenden Autoren des 18. Jahrhunderts geworden ist. Und als solcher figuriert er auch in unserer Vorlesung als Verfasser eines der Hauptwerke des 18. Jahrhunderts.

Zeit seines Lebens blieb Giacomo Casanova Venedig mit allen Fasern seiner Existenz verbunden. Das damals recht freizügige Klima der Stadt der Inseln formte und prägte ihn von Grund auf. Zugleich kann er als das bezeichnet werden, was man im 18. Jahrhundert einen „cosmopolite“ oder im Deutschen einen „Weltbürger“ nannte, obwohl er Europa - die Alte Welt - nie verließ. Casanova war ein solcher europäischer Weltbürger in eben jenem Sinne des Spaniers José Cadalso, als dass sich der illustre Venezianer als typischer Vertreter jener französisch gebildeten und französischsprachigen Elite in der internationalen République des Lettres zwischen den Ländergrenzen hin- und herbewegte. Es war die feudalistische Zeit vor Beginn eines bürgerlichen Zeitalters der Nationalismen. Unter diesem Gesichtspunkt war Casanova sehr wohl eine repräsentative Figur für die Eliten des europäischen Jahrhunderts der Aufklärung. Es handelt sich um eine Welt des Ancien Régime, die mit dem Ende des Jahrhunderts in weiten Teilen Europas - von einem restaurativen Intermezzo einmal abgesehen - zu existieren aufhörte.

Als Giacomo Casanova mit der Niederschrift seiner in französischer Sprache abgefassten Histoire de ma vie im Jahr 1789 oder spätestens 1790 begann, blickte er auf einen langen Zeitraum zurück, den er ganz im Sinne der Memoiren seiner Zeit - wie auch der modernen Autobiographie, die mit Jean-Jacques Rousseaus Confessions ihren eigentlichen Beginn und ersten Höhepunkt erst 
wenige Jahre zuvor hatte - inhaltlich immer stark an großen Persönlichkeiten ausrichtete, denen er begegnet war, zugleich aber natürlich gerade den amourösen Geschichtchen und Geschichten einen großen Teil seiner verschriftlichten Aufmerksamkeit widmete. Casanova war auch in diesem Sinne ein Kind seiner Zeit und mehr noch: auf der Höhe seiner Zeit. Denn seine Histoire de ma vie trägt alle Zeichen einer zwar feudalistischen politischen Grundauffassung, weist zugleich aber auch untrügliche Indizien moderner Subjektivität auf.

Man hat mit Rückgriff auf seine eigene Formulierung auch zu Recht von einer genießenden Niederschrift der ,Memoiren“ gesprochen, die keine Memoiren im klassischen Sinne waren. Denn Casanova hat ganz offensichtlich dieses Verfassen und die Erinnerungen und Ausgestaltungen, die er gegen Ende seines Lebens zu Papier brachte, selbst sehr genossen. Mit einer Wendung von Roland Barthes könnte man diesen Reisebericht seines Lebens ganz in das Zeichen einer „Lust am Text“ stellen, die alle Seiten dieses Texts durchdringt. Casanova schwelgte nicht nur in seinen Erinnerungen, sondern auch in seinen Fähigkeiten, diese Geschichte des eigenen Lebens facettenreich zu Papier zu bringen.

Zugleich entstand das, was man mit Philippe Lejeune ${ }^{12}$ einen autobiographischen Pakt nennen könnte: Der Autor steht mit seinem Namen dafür ein, dass es sich bei dem Ich, dem wir in diesem Buch begegnen und das als Verfasser auf dem Buchdeckel steht, tatsächlich um den realen, textextern referentialisierbaren Autor mit Haut und Haaren handelt. Wir wissen freilich aus unserer Begegnung mit Jean-Jacques Rousseaus Les Confessions, dass es sich beim autobiographischen Schreiben um ein Oszillieren zwischen Fiktion und Diktion handelt, das wir mit dem Begriff der Friktion ${ }^{13}$ belegt haben.

Denn wichtig ist für uns an dieser Stelle, dass es beim autobiographischen Schreiben kein monolithisches Ich gibt, sondern dass es sich in mindestens zwei Ichs aufspaltet, die miteinander in engster Verbindung stehen: erstens in das erzählende Ich, das sich an seine früheren Wanderungen und Erfahrungen erinnert, und zweitens in das erinnerte Ich, das die Situationen erlebt und durchlebt, welche später dann vom erzählenden Ich ,erzählt‘ beziehungsweise in schriftlicher Form festgehalten werden. Diese beiden Figurationen des Ich erlauben es, einen spezifischen literarischen Spielraum zu schaffen, in welchem sich moderne Subjektivität friktional auszudrücken vermag.

12 Vgl. das Standardwerk von Lejeune, Philippe: Le pacte autobiographique. Paris: Seuil 1975. 13 Vgl. hierzu Ette, Ottmar: ReiseSchreiben. Potsdamer Vorlesungen zur Reiseliteratur, S. 141-149. 
Diese Grundkonstellationen charakterisieren das Schreiben von Giacomo Casanova, das im Übrigen wie ein später Rückblick auf das 18. Jahrhundert und damit auf das Zeitalter der Aufklärung wirkt. Von der spezifischen Memoirenliteratur ist freilich noch das grundlegende Element vorhanden, all jene historischen Figuren aufzulisten, denen das Ich im Verlauf der Geschichte seines Lebens begegnet ist. Es gibt also schon im 18. Jahrhundert frühe Mischformen, welche die Gattungsentwicklung der Autobiographie ganz entscheidend mitgeprägt haben und die auf andere Weise noch in den zeitgenössischen Formen autofiktionalen Schreibens vorhanden sind.

Eben diese Gattungsmischung ist in Giacomo Casanovas Histoire de ma vie ausgezeichnet zu beobachten - sogar in einem sehr starken Maße, da sich in der Tat bei ihm die autobiographischen, die memoirenspezifischen und die reiseliterarischen Gattungscharakteristika gleichsam wechselseitig verstärken. Die Textdiegese, also der raum-zeitliche Bereich, der in der Geschichte meines Lebens ausgespannt wird, endet also keineswegs mit dem Jahr 1774, der Rückkehr nach Venedig, in der Casanova im Grunde jene zweite Phase zu Ende gehen sah, von der zu berichten und zu erzählen dem alten Mann noch Freude machte. So können Sie es zwar in allen literaturwissenschaftlichen Darstellungen lesen, die mit unterschiedlicher Akzentsetzung zur Geschichte meines Lebens verfasst wurden, doch wird dabei ein wesentliches Element übersehen.

Denn ,natürlich“ wird die Situation des schreibenden, des erzählenden Ich immer wieder eingeblendet, wobei diese Position auch durch die Reflexionen, die metatextuellen Einschübe im Text immer wieder in besonderem Masse erscheint und die entsprechenden historischen, kulturellen, erotischen und anderen Erfahrungen einbringt. Wir sehen so ein gewiss stilisiertes schreibendes und erzählendes Ich bei der Arbeit. Es ist ständig im Begriff, sich über lange Zeiträume seines Lebens hinweg zu erinnern, so dass diese Phase der langen Niederschrift im Alter auf dem nordböhmischen Schloss Dux im Text selbst sehr wohl präsent ist. Bis zu seinem Tode war Casanova mit der Fertigstellung und Überarbeitung seiner Memoiren beschäftigt - Eine wichtige Dimension seiner literarischen Arbeit war gleichsam seine Suche nach der verlorenen Zeit!

Nachdem wir nun schon das Ende dieser Niederschrift kennengelernt und es mit der Gesamtstruktur von Leben und Werk Giacomo Casanovas in Verbindung gebracht haben, sollten wir am besten nun mit dem Beginn des umfangreichen zwölfbändigen Textes weitermachen, der erst lange Zeit nach Ableben des Verfassers zunächst in deutscher Übersetzung ab 1822 bei Brockhaus in Leipzig zu erscheinen begann. Ich habe mich daher auch bei meinen Zitaten an die Neuausgabe dieser Leipziger Edition gehalten. Denn die Veröffentlichungsgeschichte der Memoiren ist durchaus kurios und endet nicht mit dem erwähn- 
ten Aufkauf des französischen Manuskripts für einen Millionenbetrag durch die Pariser Nationalbibliothek.

Der große Erfolg dieser recht problematischen Erstausgabe, von der aus paradoxerweise wieder zurück ins Französische übersetzt wurde - die Nachfrage war so groß, dass im Laufe der Zeit in Frankreich wie in Deutschland jeweils mehr als einhundert verschiedene Ausgaben erschienen - stellte alle Erwartungen in den Schatten. Er verankerte bereits frühzeitig den Namen des frankophilen Italieners im kollektiven Gedächtnis der abendländischen Welt als eine Art Prototyp oder repräsentativer Figur des männlichen Verführers in der Literatur - So werden Sie auch erstmals auf den Namen Casanova gestoßen sein! Aber war es wirklich dieses Bild, das Casanova von sich selbst transportiert sehen wollte? Viel gäbe es dazu zu sagen, doch sollten wir uns nun mit der Vorrede beschäftigen!

Ihr ist als Motto ein unvollständiges Cicero-Zitat vorangestellt, das am Ende dieser Vorrede erneut bemüht wird, so dass eine Art Kreisstruktur entsteht und jenes Motto zusätzlich in seiner Bedeutung herausgehoben wird: „Wer sich nicht selbst kennt, weiß gar nichts.“ Damit ist das zentrale Motiv der Selbsterkenntnis, der Selbsterfahrung von Beginn an in den Text eingeblendet: ein Grundelement moderner Subjektivität. Vielleicht wäre hier mehr das Bild zu suchen, das Casanova philosophischerweise von sich am liebsten verbreiten wollte - was er durchaus mit vollem Recht tun konnte! Nach diesem Motto heißt es dann:

Ich erkläre meinem Leser von vornherein, dass ich bei allem, was ich zeit meines Lebens an Gutem oder Bösem getan habe, sicher bin, entweder verdienstvoll gehandelt oder gesündigt zu haben, und dass ich mich deshalb für ein mit freiem Willen begabtes Wesen halten muß. [...] Ich glaube an die Existenz eines unkörperlichen Schöpfergottes, der Herr alles Gestaltgewordenen ist. Der Beweis dafür, dass ich nie daran gezweifelt habe, ist für mich die Tatsache, dass ich stets auf seine Vorsehung zählte, in allen meinen Nöten durch das Gebet Zuflucht bei ihm suchte und auch stets erhört wurde. [...]

Der Leser, der zum Nachdenken neigt, wird aus diesen meinen Erinnerungen ersehen, dass ich nie auf ein bestimmtes Ziel zusteuerte und deshalb nur dem System folgte wenn es überhaupt eines ist -, mich dahin treiben zu lassen, wohin der Wind blies. Wie viele Wechselfälle birgt doch diese Unabhängigkeit von jeglicher Methode in sich! Meine Mißgeschicke haben mir ebenso wie die Glücksfälle gezeigt, dass auf dieser gleichermaßen körperlichen wie moralischen Welt das Gute aus dem Bösen hervorgeht, wie das Böse aus dem Guten. Meine Irrwege werden den Nachdenklichen die entgegengesetzten Pfade weisen oder sie die hohe Kunst lehren, sich stets im Sattel zu halten. Es gilt nur, Mut zu haben, denn Kraft ohne Vertrauen ist zu nichts nütze. Ich habe oft erlebt, dass mir durch einen unbedachten Schritt, der mich eigentlich an den Rand des Abgrunds hätte führen müssen, das Glück in den Schoß fiel. [...]

Trotz des Vorrates an trefflicher Moral als natürlicher Frucht der in meinem Herzen eingewurzelten göttlichen Prinzipien, bin ich ein Leben lang ein Opfer meiner Sinne gewesen. Vom rechten Weg abzuweichen, machte mir Vergnügen, und ich habe fortwährend Fehler begangen [...]. Aus diesem Grunde hoffe ich, lieber Leser, dass du, weit davon 
entfernt, in meiner Geschichte schamlose Prahlerei zu entdecken, darin solche Züge findest, die einer Generalbeichte zustehen, obschon du im Stil meiner Berichte weder das Gehabe eines Büßers noch das Schuldgefühl eines Menschen finden wirst, der errötend über seine losen Streiche Rechenschaft ablegt. ${ }^{14}$

Die Grundhaltung, in welcher Casanova die erwünschte Rezeption seines Textes sieht, ist die der Wahrnehmung als Beichte und damit als „Confession“. Dass er dabei nicht das Gewand des Büßers wählt, ist etwas, das zweifellos seinem Naturell entspricht, und präsentiert eine Haltung, die zugleich aber auch die von Jean-Jacques Rousseau gegenüber seinen autobiographischen Schriften war. Auch letzterer war weit davon entfernt, das Büßergewand anzulegen, um sein Leben zu rechtfertigen; vielmehr trat er erhobenen Hauptes und mit dem Buch seiner Confessions in der Hand herausfordernd vor den höchsten Gott. Dieser möge seinem herausragenden Leben Gerechtigkeit widerfahren lassen! Die Parallelen zwischen den autobiographischen Texten Casanovas und Rousseaus sind trotz allen literarischen Gattungsunterschieden offenkundig. Casanova stand Rousseau vielleicht näher, als ihm selbst bewusst war und als ihm selbst vor dem Hintergrund seiner Darstellung des Genfer Philosophen vor Augen stand.

In dieser etwas längeren Passage gibt es eine ganze Reihe von Charakteristika, die wir in der Folge immer wieder in Casanovas Histoire de ma vie antreffen werden. Zum einen findet man am Anfang und am Ende der hier aufgeführten Überlegungen direkte Anreden an den Leser, der nicht notwendig nur ein männlicher sein musste. Denn wir wissen heute, dass die erotische Literatur im 18. Jahrhundert gerade auch von Frauen - Marie-Antoinette ist hier nur ein besonders bekanntes Beispiel - sehr goutiert und gerne gelesen wurde. Freilich war die tatsächliche Zugänglichkeit des Casanova'schen Lebensberichts im 18. Jahrhundert höchst eingeschränkt.

Es scheint sich auf textinterne Weise eine direkte Beziehung zu bilden zwischen dem realen Autor und dem Ich-Erzähler einerseits - die gemäß des autobiographischen Pakts stillschweigend miteinander identifiziert werden - und dem expliziten (und allen impliziten) Leserfiguren andererseits. Dabei muss man dieser expliziten Leserfigur laut Ich-Erzähler (und hier besonders dem erzählenden Ich) ein gewisses Alter und eine gewisse Lebenserfahrung zuschreiben: Denn für die Jugend habe er fürwahr nicht geschrieben! Ich werde dennoch Ihnen gegenüber keine größeren Vorsichtsmaßnahmen walten lassen, denn Casanova ist ganz sicherlich in Sachen Erotik ein harmloses Lesevergnügen

14 Casanova, Giacomo: Geschichte meines Lebens, Bd. 1, Vorrede, S. $63 \mathrm{ff}$. 
Schließlich befinden wir uns laut Vorwort eindeutig auf dem Gebiet der Philosophie, auch wenn Casanova ein System in seinen Lebens-Untersuchungen beim besten Willen nicht erkennen will. Vielmehr wendet er sich explizit von jeder stringenten Methode, von jedem monologischen System ab und rechnet sich keiner Philosophie zu, die irgendeinem Systeme folgt. Im Gegensatz dazu macht er den Fehler als ein grundlegendes Erkenntnisinstrument aus: Man könnte sagen, dass Casanova durch seine vielen von ihm begangenen Fehler zwar vielfältig gescheitert ist, aber zugleich auch dadurch gescheiter wurde. Man könnte vielleicht sogar so weit gehen, Casanova einer Poetik des Fehlers, ja einer Poetologie des Fehlers im System zuzurechnen, wie sie vor allem zu Beginn des 21. Jahrhunderts aufmerksam diskutiert worden ist. ${ }^{15}$ Denn das erzählende Ich erklärt offenkundig den Fehler zu einer zentralen Erkennungsmarke seines eigenen Lebens: zumindest aus der Position des weise gewordenen erzählenden Ich, das seine Memoiren auf Schloss Dux verfasst. Leben und Schreiben stehen so bei Casanova in einem Wechselverhältnis des Lernens, das sich über Jahrzehnte seiner Lebensgeschichte erstreckt und auch im Alter noch nicht zu Ende ist.

Daneben findet sich eine schon zu Beginn recht deutlich prononcierte Absicht, das Christentum und den christlichen Glauben mit dem Libertinage, mit der Freizügigkeit in philosophischen wie in erotischen Dingen, in Einklang und Übereinstimmung zu bringen. Es handelt sich dabei um eine Vorstellung, die Casanova - der ja einst eine Tonsur besessen hatte - immer wieder der Erwähnung wert ist. Die Verfolgungen durch die venezianische Inquisition mögen für den alternden Italiener lehrreich gewesen sein. Doch den Anspruch auf ein gottgefälliges Leben hat er auch im Angesicht seines baldigen Todes bei weitem nicht aufgegeben.

Casanova betont in seinem Vorwort, dass er nie auf ein bestimmtes Ziel zugesteuert sei und nie eine klare Route verfolgt habe, sondern die jeweiligen Gelegenheiten stets beim Schopfe packte, sobald sie sich ihm darboten. In diesem Sinne stimmt er mit jenem aktiven Fatalismus mitsamt seinen ständigen Kurswechseln überein, wie ihn Diderots Jacques le fataliste auszeichnet. Casanova ist wie Jacques zwar nicht der Herr über alle Dinge, wohl aber sein eigener Herr. Das Fehlen einer Methode ist etymologisch gesehen das Fehlen eines klaren, geraden Weges, den er gerade nicht befolgte, um auf alles spontan und unvermittelt reagieren zu können. $\mathrm{Zu}$ dieser Art eines aktiven Fatalismus braucht

15 Vgl. hierzu unter anderem Ingold, Felix Philipp / Sánchez, Yvette (Hg.): Fehler im System. Irrtum, Defizit und Katastrophe als Faktoren kultureller Produktivität. Göttingen: Wallstein Verlag 2008. 
es jedoch eine Menge Selbstvertrauen und auch Mut, den sich Casanova selbst sehr wohl bescheinigt.

Das Einräumen einer Achtung der obersten religiösen Instanz hat selbstverständlich auch mit der Frage der Zensur und der Gepflogenheiten im 18. Jahrhundert zu tun. Aber Casanova plante offenkundig nicht - obwohl er dann doch noch wohl auf Druck seiner Freunde einen erfolglosen Versuch der Veröffentlichung unternahm -, seine Lebenserinnerungen noch vor seinem Ableben zu veröffentlichen. Für ihn selbst war nicht die Veröffentlichung, sondern die Niederschrift der Geschichte seines Lebens das Entscheidende. Wir können gleichwohl eine intensive Inszenierung der Beziehung zwischen Autor und Leserschaft von Beginn an konstatieren. Sie wird sich durch den gesamten Text ziehen und deutet auf einen Schriftsteller, der sehr wohl die Grenzen zwischen der Memoirenliteratur und der modernen Autobiographie bewusst überschritt und Elemente beider Gattungen miteinander mischte. Als ein Prahlhans wollte der Ich-Erzähler freilich in den Augen der geneigten Leserschaft nicht dastehen. Und so sollten wir es auch vermeiden, die Histoire de ma vie als Protzen mit der eigenen sexuellen Potenz misszuverstehen! Diese ist freilich die Voraussetzung dafür, die unterschiedlichen Facetten eigener Subjektivität, vor allem aber auch deren soziopolitischen Kontexte und die Gesellschaften Europas im Aufklärungszeitalter darzustellen.

Zur spezifischen Art des Fatalismus Casanovas gehört, dass er im Verlauf seines Lebens immer wieder von seinen eigenen Sinnen überwältigt worden sei. Der Venezianer zeigt sich freilich weit davon entfernt, dies zu bedauern: Seinen Sinnen habe er an entscheidenden Punkten seines Lebens immer wieder nachgegeben und sei ihren Lockrufen gefolgt! Man könnte daher die These wagen, dass Casanova als sinnlich ausgerichteter Mensch nicht einer rationalen Orientierung, sondern stets einer unmittelbaren Lusterfüllung gefolgt sei und sich daraus auch die vektorielle Anlage seiner gesamten Lebensbewegung ergeben habe: ein ständiges Hin und Her, geprägt von zahlreichen Abwegen und Holzwegen, auf denen er das Europa seiner Zeit durchquerte. Die Parallele zur angeführten Eröffnung von Diderots Jacques le fataliste et son maître ist offenkundig: „Woher kamen sie? Vom nächstgelegenen Ort. Wohin gingen sie? Weiß man denn, wohin man geht?“

Nur auf den ersten Blick ist die Szene belanglos, welche eine erste wichtige Reisebewegung des erzählten Ich schildert; tatsächlich aber erweist sie sich bei genauerer Lektüre als überaus hintergründig. diese erste Reise erfolgt nicht in Gesellschaft einer Geliebten, wie man vielleicht erwarten könnte, sondern vielmehr der eigenen Mutter. Sie begleitet ihren Sohn auf dessen Reise von Venedig nach Padua an Bord eines Schiffs, des Burchiello, das mitten in der Nacht seine Fahrt beginnt. Das Ziel der Reise wird angesteuert, weil die Ärzte empfohlen 
haben, den Jungen von Venedig zu entfernen, da das dortige Klima an seinen starken Nasenblutungen schuld sei - ein Leiden, das Casanova im Verlauf seines langen Lebens übrigens niemals wirklich besiegen konnte. Wolle man den Jungen nicht verlieren, so hatten die Ärzte geraten, dann müsse man ihn in ein anderes Klima bringen.

Die angestrebte Luftveränderung führte die kleine Reisegruppe in das nicht sehr weit entfernte, aber klimatisch durchaus differente Padua, wo der Junge bei einer Pflegefrau in die Obhut gegeben wurde, die ihn dann zur Schule schicken und über ihn wachen sollte. Interessant ist nun, wie die Reise dargestellt und fokalisiert wird und inwieweit sie gleichsam eine Mise en abyme vieler anderer, nachfolgender Reisen darstellt:

Sobald es tagte, stand meine Mutter auf und öffnete ein Fenster gegenüber meinem Bett. Die Strahlen der aufgehenden Sonne trafen mein Gesicht und ließen mich die Augen aufschlagen. Das Bett war so niedrig, dass ich das Land nicht sehen konnte. Ich erblickte durch das Fenster nur die Wipfel der Bäume, mit denen die Ufer des Flusses durchweg gesäumt sind. Das Schiff schwamm dahin, doch mit einer so gleichmäßigen Bewegung, dass ich davon nichts spüren konnte. Deshalb setzten mich die Bäume, die rasch vor meinen Augen vorbeizogen, in Erstaunen. „Ach, liebe Mutter!“ rief ich. „Was ist denn los? Die Bäume wandern ja!“

In diesem Augenblick kamen die beiden Herren herein, und als sie mich so verdutzt sahen, fragten sie, was mich denn so beschäftige. „Wie kommt es“, fragte ich zurück, „dass die Bäume wandern?“

Sie lachten; meine Mutter aber seufzte und sagte mitleidig zu mir: „Das Schiff bewegt sich und nicht die Bäume. Zieh dich jetzt an.“

Ich begriff augenblicklich, wie diese Erscheinung zustande kam, und mit meinem erwachenden und ganz unvoreingenommenen Verstand dachte ich folgerichtig weiter. „Dann ist es also möglich“, sagte ich zu ihr, ,dass sich auch die Sonne nicht bewegt, sondern dass wir es sind, die von Westen nach Osten wandern." Meine gute Mutter jammerte über so viel Dummheit, und Signor Grimani beklagte meinen Unverstand; ich stand ganz verstört und traurig da und war dem Weinen nahe. Nur Signor Baffo gab mir wieder neuen Mut. Er kam auf mich zu, küßte mich zärtlich und sagte: „Du hast recht, mein Kind, die Sonne bewegt sich nicht. Verliere nicht den Mut, bilde dir stets dein eigenes Urteil und laß die andern ruhig lachen.“ [...] Das war die erste wirkliche Freude, die ich in meinem Leben genoß. ${ }^{16}$

Die vektoriellen Bewegungen der Reise sind der Ort einer ersten eigenständigen Erkenntnis des Ich und zugleich der Ort eines Wissens aus der Bewegung. Dies wird auch für das künftige Leben des Ich eine Leitschnur bleiben: Mit der Bewegung, mit der Veränderung der Perspektive, ist Erkenntnis - und zwar lustvolle Erkenntnis - verbunden. Denn es ist auf der Reise, durch den Blick aus dem Fenster des fahrenden Schiffs, dass der kleine Junge auf grundlegende Fragen

16 Casanova, Giacomo: Geschichte meines Lebens, Bd. 1, S. 87 f. 
und Antworten, die das ganze Universum betreffen, gebracht wird und zugleich lernt, dass man für sich allein denken muss, ohne den anderen einfach nachzugeben. Casanova markiert an diesem Augen-Blick der Reise den Ursprung seines unabhängigen, eigenständigen Denkens, das auf die Reaktionen der Anderen nur wenig Rücksichten nimmt.

Entscheidend in dieser Szene ist die Bewegung, die Veränderung der Perspektive und die verschiedenen Standpunkte, die ein Beobachter-Ich sowie andere Figuren gegenüber demselben Gegenstande einnehmen können. Die Erkenntnis ist also ein Kind der Bewegung, eine Frucht des Reisens, das von so zentraler Bedeutung für den Ich-Erzähler ist, weil sich aus dieser Mobilität zugleich auch sich verändernde Blickwinkel und damit eine Multiperspektivität ergeben. Die äußere wie auch die innere Bewegung sind von zentraler Bedeutung, um den gesamten Text der nachfolgenden Histoire de ma vie verstehen $\mathrm{zu}$ können: Sie erst eröffnen jene verschiedenartigen Perspektiven auf die Welt, welche im nachfolgenden Bericht eines Lebens auf der Suche nach Liebe quer durch Europa effektvoll in Szene gesetzt werden.

Dabei ist der lustvolle Genuss, das Genießen, die Freude an der Erkenntnis ein ganz zentraler Faktor. So wie das Schreiben des alten Casanova ein genießendes ist, so ist auch das Prinzip Lust ein zentrales Handlungsmotiv für das erzählte Ich, das sich immer wieder gerne von seinen Sinnen überwältigen lässt. Erkenntnis ist ein ebenso lustvoller Prozess wie die Sexualität, welche auf diesen Seiten recht freizügig ausgelebt werden kann. Die Histoire de ma vie ist ein genießender Text, ein „texte de plaisir“, der lustvoll niedergeschrieben und lustvoll gelesen werden kann. Die Lust am Text ist ebenso für die Niederschrift wie für die Lektüre, ebenso für die Produktion wie für die Rezeption der Geschichte meines Lebens von überragender Bedeutung.

Doch nicht allein das Dionysische, sondern auch das Apollinische ist auf diesen Seiten von Beginn an und ab dieser Szene einer ersten Reise mit der Mutter gegenwärtig. Damit wird die Reisebewegung gleichsam zum Erkenntnismotor eines Denkens und eines Schreibens (wie auch eines Lesens), das sich beständig in Bewegung weiß und alten Vorurteilen die eigene Er-Fahrung des Ich entgegenstellt. Das Reisen ist mit Erkenntnis und Freude, mit Wissen und Lust und Lust am Wissen gepaart. Nichts vermag den stetigen Erkenntnisprozess des Ich-Erzählers aufzuhalten. In seiner Freiheit, in der Freiheit seiner Bewegungen, wird lustvolle Erkenntnis zum Ziel eines Subjekts, das sich unabschließbar um seine Objekte dreht. Und es ist ein modernes Subjekt, für welches die Selbstreflexion wie auch die Abgrenzung von allen anderen Subjekten entscheidende Aspekte der Selbstkonstituierung als Individuum sind. Die Modernität der Reise- und Erkenntnisbewegungen geht mit der Modernität der Subjektbildung Hand in Hand. 
Die gesamten hermeneutischen Bewegungsfiguren der Histoire de ma vie sind von Diskontinuitäten und Abbrüchen gekennzeichnet. Einkerkerungen, Ausbruchsversuche, Ausweisungen und fluchtartiges Verlassen sind wie beim neuspanischen Dominikaner Fray Servando Teresa de Mier narrative Elemente, die sich in diesem Leben als Reise, in diesem Lebensbericht als Reisebericht ständig wiederholen. Bei Fray Servando wie bei Casanova ist hierbei die Nähe zur „Novela picaresca“ offenkundig, zum Schelmenroman des 17. Jahrhunderts. Beide stellen auf eine jeweils umfassende Weise das Europa des Aufklärungszeitalters dar.

Giacomo Casanovas Lebensgeschichte ist eine lange Beichte, aber vorgetragen in einem stolzen, selbstbewussten Ton - niemals in dem eines Büßers, der zutiefst sein Leben bereut hätte. Sie trägt damit auch auf dieser Ebene Züge der Novela picaresca, aber weit mehr noch jene einer modernen Subjektivität, welche sich bewusst gegen die herrschenden gesellschaftlichen Normen und Konventionen stellt. Wie beim „pícaro“ finden wir auch bei Casanova ein beständiges Queren unterschiedlichster sozialer Stände und Gruppen, von den niedersten Klassen - also etwa den Bauern, zu denen auch die hübschen Bauernmädchen gehörten, die Casanova keineswegs verachtete - bis hinauf zu den höchsten Höhen der Gesellschaft, zu den Fürsten und vor allem Fürstinnen, Herzögen und Herzoginnen, an den großen wie den kleinen Höfen Europas.

Der eigentliche Treibstoff für seine Reisen und alle Bewegung ist das Begehren, wohl weitaus mehr noch als die Lust oder gar die Wollust, die Casanova sich von seinen jeweiligen Eskapaden und Abenteuern erhofft. Giacomo Casanova ist einer, der sich - zumindest nach Aussage seines Ich-Erzählers treiben lässt im Vektorenfeld eines Begehrens, das ständig neue Objekte findet und wieder aus den Augen verliert. In ihm ist ein unmäßiges Wollen, ständig neue Umgebungen, ständig neue Geliebte, ständig neue Erfahrungen und Erlebnisse zu sammeln und dadurch Neues sinnlich zu erleben. Für dieses Begehren gibt es keine Grenze, keinen Überdruss, keine Langeweile. Denn wie das Ein- oder Ausatmen wiederholt sich bei ihm auch die Liebe niemals.

Dabei sind Casanovas erotische Besitzergreifungen und heterosexuelle Inbesitznahmen ebenso wie sein ausgeprägtes Nomadentum von erstaunlicher Haltbarkeit und Widerstandsfähigkeit. Erst spät stellen sich bei ihm auf den verschiedensten Ebenen Ermüdungserscheinungen ein, wobei in der Forschungsliteratur, aber auch schon bei Casanova selbst das Jahr 1763 - und damit sein Aufenthalt in London - als ein Jahr der Wende dargestellt wird. Mag sein, dass ihn eine unerfüllte Liebe zu einem jungen, kaum achtzehnjährigen Mädchen fast in den Selbstmord und damit an einen Punkt stärkster Selbstreflexion geführt hatte. Casanova musste sich der Vektoren seines Begehrens wieder von neuem versichern - und dies gelang! 
Dass der Treibstoff der Reisebewegungen im Grunde immer ein Triebstoff war, macht Casanova mit seinem Verweis auf die sinnliche Dominanz seiner Lebenserfahrungen deutlich. Dieser sinnliche und zugleich sensualistische Aspekt seiner Lebensphilosophie ist vielfach gedeutet worden. Entsprechend stark ist auf dieser Bedeutungsebene auch die sinnliche Wahrnehmungswelt des Texts ausgestattet, betont der weitgereiste Venezianer doch schon in der Vorrede seines Werks, dass jede Frau, in die er sich verliebte, stets für ihn angenehm duftete; und dass er dies umso mehr genoss, je mehr sie bei seinen zärtlichen Bemühungen ins Schwitzen kam. Gerade dieser olfaktorischen und taktilen Sinnenfreude dürfen wir bei der Analyse seines Lebensberichts eine größere Aufmerksamkeit schenken, kommt ihr doch unter Einbeziehung aller körperlichen Flüssigkeiten eine gleichsam dionysische Qualität zu.

Im Grunde ist der Lebensbericht also ein Reisebericht und der Reisebericht ein Liebesbericht aus dem Vektorenfeld eines unendlich wiederholten und erneuerten Begehrens. Die Bewegungen im Text und im Leben überlagern sich, die Mobilität schreibt sich ein in ein immer komplexer werdendes Vektorenfeld, das vom eigenen Begehren unter Spannung gehalten wird. Das Leben selbst erscheint als Reise - ein Topos, den wir seit der Antike in der abendländischen Literatur verfolgen können. Doch die Lebensreise des Giacomo Casanova war eine besondere!

Die Geschichte meines Lebens ist zudem ein hochgradig selbstreflexiver Text. Giacomo Casanova gibt in seiner Vorrede klare Hinweise zur Art der Niederschrift und seinem Gattungsverständnis. Die nachfolgenden Reflexionen zeugen vom hohen Grad an Bewusstheit und Selbstreflexion bei dem galanten Philosophen:

Ein antiker Autor belehrt mich in schulmeisterlichem Ton: „Wenn du nichts vollbracht, was das Aufschreiben lohnt, so schreibe wenigstens etwas, das wert ist, gelesen zu werden.“ Diese Vorschrift ist so schön wie ein in England geschliffener Diamant reinsten Wassers, aber sie betrifft mich nicht, weil ich weder die Geschichte eines berühmten Mannes noch einen Roman schreibe. Ob wert oder unwert, mein Leben ist mein Stoff, und mein Stoff ist mein Leben. Da ich es gelebt habe, ohne je daran zu denken, mich könnte einmal die Lust packen, es aufzuzeichnen, mag es ein gewisses Interesse besitzen; das aber hätte es wohl kaum, wenn ich mein Leben in der Absicht geführt hätte, es in meinen alten Tagen niederzuschreiben und, was weit mehr ist, es auch noch zu veröffentlichen. ${ }^{17}$

Casanova situiert seinen eigenen Text zwischen den Memoiren eines großen Mannes und einem Roman: Beides aber habe er nicht geschrieben! Es geht folglich um ein Ich, das wie im Falle Rousseaus kein in der Gesellschaft berühmter

17 Casanova, Giacomo: Geschichte meines Lebens, Bd. 1, Vorrede, S. 66 f. 
Mann ist, sondern um eines, das es nach eigenem Gutdünken wert ist, gelesen zu werden, auch wenn es keinen großen Namen trägt und nicht von fürstlichem Geblüte ist. Diese Passage, die mit einem Zitat von Plinius dem Jüngeren beginnt und mit einem ironischen Verweis auf die keineswegs berühmte englische Diamantenschleifkunst weitergeht, wird danach von einer Datierung des Vorworts explizit auf das Jahr 1797 fortgeführt, in welchem Casanova den bereits erwähnten Genuss bei der Niederschrift seines Texts hervorhebt. Es ist ein Blick zurück am Ende eines Jahrhunderts, das sicherlich nicht das Jahrhundert Casanovas war, das der weitgereiste Venezianer aber bezogen auf Europa wie nur wenige einzufangen verstand. Es ist zudem der Blick zurück auf eine Welt, die im Begriff stand, am Ende dieses Jahrhunderts hinter dem Horizont zu verschwinden.

Nachdem man in einer kontroversen Rezeptionsgeschichte im 19. Jahrhundert bisweilen die gesamte Geschichte meines Lebens für Erfindung und pure Fiktion, deren Verfasser sogar für eine erflunkerte Figur gehalten hatte, belegten die Forschungen insbesondere im 20. Jahrhundert eindrucksvoll, wie präzise die Erinnerungen und Gedächtnisleistung des Venezianers waren. Sie belegten, wie genau er sich - selbstverständlich unterstützt von seinem Tagebuch - an bestimmte Abläufe erinnerte, auch wenn sich bisweilen Fehler und Lücken in seiner „narratio“ nachweisen lassen. Aber dies war bei einem Abstand von mehreren Jahrzehnten wahrlich keine Überraschung! Wie Jean-Jacques Rousseau konnte er mit dem Buch seines Lebens in der Hand vor seinen Schöpfer wie vor seine Leserschaft treten und bei aller Friktionalität autobiographischen Schreibens doch für die historische Wahrheit des von ihm verfassten Buchs plädieren. Auch Casanova konnte wie Jean-Jacques dabei hinzufügen, dass er wie kein anderer Mensch gemacht sei, und dass es auch nach ihm niemals einen Menschen geben werde, der ihm gliche.

Zweifellos machte Giacomo Casanova durch seine spektakuläre Flucht aus den Bleikammern - die er nachträglich 1788 beschrieb und separat in Buchform veröffentlichte, später aber in veränderter Form in seine Histoire de ma vie miteinbezog - bei einer europäischen Öffentlichkeit erstmals auf sich aufmerksam. Casanova war folglich durchaus ein Gedächtniskünstler, dem es um eine möglichst präzise Darstellung seiner Lebens- und Liebesabenteuer ging. Daraus aber nun den wie in einem Pendelschlag umgekehrten Schluss zu ziehen, es handle sich bei der Histoire de ma vie ganz einfach um einen dokumentarischen Text, der sich in einen direkten mimetischen Bezug zur außersprachlichen Wirklichkeit setzen lasse, wäre ohne Zweifel ebenso irreführend wie ein Verweis in das Reich der Fiktion: Dies würde der Komplexität der friktionalen Anlage dieses Erzähltexts nicht gerecht! 
Kein Zweifel kann daran bestehen, dass Casanova, der übrigens im Alter neben vielen anderen Schriften noch einen utopischen Roman verfasste, sich selbst als „philosophe“, als „honnête homme“ und vor allem als „homme de lettres“ verstand und in der Tat ein genuiner Bestandteil jenes Siècle des Lumières war, dass so stolz auf seine kritische Rationalität schien. Er sah sich in der République des Lettres als einen Schriftsteller, der zwar als italienischer Muttersprachler im Französischen mit mancherlei Tücken und fehlgeleiteten Italianismen zu kämpfen hatte, aber gleichwohl über ein hohes Talent als Literat von europäischem Format verfügte. Längst ist es in der Forschung unstrittig, den wagemutigen Venezianer als einen talentierten und versierten Schriftsteller anzusehen und die literarische Qualität seines gesamten Texts nicht länger in Zweifel zu ziehen. Die Konsultation seines Werks ist unabdingbar für all jene, die sich einen aussagekräftigen Eindruck vom intimen Leben einer internationalisierten Feudalgesellschaft in Europa zu verschaffen versuchen.

Sie suchen nach einem Portrait des preußischen Königshofs zu Potsdam, um sich ein lebendiges Bild der Gesellschaft um den Preußenkönig Friedrich den Großen machen zu können? Fragen Sie nach bei Giacomo Casanova, er ist ein guter Gewährsmann! Ich hatte schon erwähnt, dass seine Erfahrungen 1763 in London - insbesondere mit einer ihm nicht gefügigen jungen Dame - nicht die besten waren, so dass er später dieses Jahr 1763 als einen Wendepunkt in seinem Leben ansah. Er verließ schließlich im März 1764 überstürzt die englische Hauptstadt, um zurück auf den Kontinent zu kommen, von wo aus er über Dünkirchen, Brüssel, Lüttich, Wesel, Minden und Braunschweig - wo er sich in der Nähe gleich die wunderbare Bibliothek zu Wolfenbüttel zeigen ließ - Magdeburg erreichte. Von dort aus brach er nach Berlin auf und machte selbstverständlich auch in Potsdam am Hofe zu Sanssouci Station. Angesichts des herausragenden Rufs des damaligen Preußenkönigs war dies zumindest für einen bestimmten Zeitraum ein fast obligatorischer Halt. Und Sie haben das Privileg, sich diese Szenerien an den Originalschauplätzen und im Park von Sanssouci perfekt vorstellen zu können!

Kein Geringerer als Friedrich der Große - der bekanntlich homosexuelle Neigungen hatte - hielt unseren Venezianer nach eigenem Bekunden für einen schönen Mann, auch wenn die Begegnung zwischen beiden nicht besonders intensiv und lange währte. Giacomo Casanova kam im Juli nach Potsdam und Berlin; im August besuchte er gemeinsam mit Friedrich dem Großen eine Kadettenanstalt, was der preußische König dazu nutzte, seinem venezianischen Gast - wie bereits berichtet - das Angebot zu unterbreiten, an dieser Kadettenanstalt als Erzieher zu arbeiten. Sie mögen daran erkennen, wie gut noch immer Casanovas Ruf war oder wie wenig sich der preußische König um diesen Ruf einen Kopf machte ... Nun, der Chevalier de Seingalt lehnte dankend ab, was wir herzlich bedauern: 
Denn wir hätten seine pädagogischen und didaktischen Schritte mit den ihm anvertrauten jungen Kadetten gerne in Erzählungen und Dokumenten der Zeit nachvollzogen.

Nein, ich kann Ihnen von keiner Liebesgeschichte, von keiner schwungvollen Affäre Casanovas in Potsdam berichten: Die Potsdamer Schönheiten scheinen auf Casanova ihre Wirkung nicht entfaltet $\mathrm{zu}$ haben. Aber hübsche Anekdoten gibt es dennoch, und ich möchte sie Ihnen auch keineswegs vorenthalten. Wo konnte Casanova in Potsdam den König der Preußen erblicken? Natürlich bei der Parade, wo sonst!

In Potsdam sahen wir den König bei der Parade; er kommandierte sein erstes Bataillon, dessen Soldaten alle in den Uhrtäschchen ihrer Hosen eine goldene Uhr hatten. So belohnte der König den Mut, den sie bewiesen hatten, als sie ihn unters Joch nahmen, wie einst Cäsar in Bithynien den Nikomedes. Man machte gar kein Hehl daraus.

Unser Schlafzimmer im Gasthof lag gegenüber einem Durchgang, den der König benutzte, wenn er das Schloß verließ. Die Läden der Fenster waren geschlossen; unsere Wirtin erzählte uns den Grund. In dem gleichen Zimmer wie wir hatte nämlich die sehr hübsche Tänzerin Reggiana gewohnt, und als der König sie eines Morgens beim Vorübergehen ganz nackt erblickt hatte, war sogleich der Befehl ergangen, dass man die Fenster schließen solle; das war schon vor vier Jahren geschehen, doch hatte man sie nie wieder geöffnet. Seine Majestät hatte vor ihren Reizen Angst gehabt; nach seiner Liebschaft mit der Barberina wollte er nichts mehr davon wissen. Später sahen wir im Schlafzimmer des Königs das Porträt dieses Mädchens, das der Cochois, der Schwester der Schauspielerin, die den Marquis d'Argens geheiratet hatte, und das der Kaiserin Maria Theresia aus ihrer Jungmädchenzeit, in die er sich verliebt hatte, weil er Kaiser werden wollte.

Nachdem wir die Schönheit und die Eleganz der Räume des Schlosses bewundert hatten, sahen wir überrascht, wie er selbst wohnte. Wir erblickten in einer Ecke des Zimmers hinter einem Wandschirm ein schmales Bett; Hausrock und Pantoffel waren nicht vorhanden. Der anwesende Diener zeigte uns eine Nachtmütze, die der König aufsetzte, wenn er erkältet war; sonst behielt er seinen Hut auf, was recht unbequem sein mußte. ${ }^{18}$

Wir können an dieser Szene eine ganze Menge an Informationen herausgreifen. Dabei ist es auffällig, dass Friedrich des Großen Leidenschaft für Männer bei den Zeitgenossen offenkundig kein Thema war, sondern man dem König allerlei Geschichten um hübsche Frauen andichtete. Offensichtlich war es dies, was man von gekrönten Häuptern erwartete, selbst oder gerade in Potsdam. Sie sehen: Wir erfahren bei dieser Art von Hofberichterstattung eine Menge Klatsch und Tratsch, was sicherlich durchaus zeitgemäß war in der gesellschaftlichen Elite des 18. Jahrhunderts! Schon damals gab es jede Menge Paparazzi, die aus erster Hand möglichst getreue Portraits des Lebens der Monarchen schießen

18 Casanova, Giacomo: Geschichte meines Lebens, Bd. 10, S. 87. 
wollten. Der König von Preußen schlief also mit Hut und hatte keine Pantöffelchen. Literatur kümmert sich also um alle Lebensumstände und zeigt uns, wie man zu einem bestimmten Zeitpunkt an einem bestimmten Ort zu leben pflegte oder auch gelebt haben könnte. Sie beschreibt uns nicht die geschichtliche Wirklichkeit, wie sie wirklich gewesen ist: Das besorgen bestenfalls schon die Historiographen. Literatur erzählt uns - ganz im Sinne des Aristoteles - wie es hätte gewesen sein können, und sie tut dies anhand des Blicks eines Menschen, der uns als Gewährsmann für die Darstellung einer gelebten Wirklichkeit dient. Dass wir dabei ganz nebenbei erfahren, dass Friedrich der Große keine Pantöffelchen trug, tut der lebendigen Darstellungsfähigkeit der Literatur keinen Abbruch.

Wir sehen zugleich, wie präzise Casanova beobachtet und darüber hinaus basierend auf seinen Notizen noch Jahrzehnte später alles festhielt, was ihm erlauben konnte, eine bestimmte Gesellschaft oder eine bestimmte Persönlichkeit zu porträtieren - hier jene von Friedrich dem Großen. Es ist schade, dass wir nicht über die Tagebücher Casanovas verfügen: Er scheint sie wohl gegen Ende seines Lebens auf Schloss Dux verbrannt zu haben. Doch die detaillierte Erinnerungsfähigkeit des Venezianers ist beeindruckend. Das zitierte Portrait in Abwesenheit des Königs wird später noch durch mehrfache Beobachtungen in presentia ergänzt: Auch von einem Dialog wird berichtet, doch können wir dies getrost beiseitelassen - dies sind die sozialen Netzwerke, wie sie im 18. Jahrhundert funktionierten und wie sie für Giacomo Casanova überlebenswichtig waren.

Es geht letzterem entgegen seines Rufs nicht ausschließlich um die Darstellung der verschiedenen Abenteuer und vor allem Liebesabenteuer, die er quer durch Europa - von der Südspitze Italiens bis nach Moskau, von Preußen bis nach England, von Polen bis nach Spanien, nicht zuletzt aber in Frankreich und Italien - zu bestehen hatte. Liest man die Histoire de ma vie vorurteilslos, dann zeigt sich, dass selbst noch die Beschreibung der Frauenzimmer - wie bei der obigen Darstellung eines solchen in Potsdam - den Blick nicht nur auf nackte Tatsachen, sondern auf soziale und kulturelle Situationen und Entwicklungen eröffnet, die ein lebendiges Bild der jeweiligen Gesellschaft projizieren. Auf diesem Gebiet kann die Bedeutung von Casanovas Geschichte meines Lebens gar nicht überschätzt werden: Sie vermittelt uns ein anschauliches Bild vom Leben einer gesellschaftlichen Elite im europäischen 18. Jahrhundert, auch wenn sie sich keineswegs auf das Dokumentarische beschränkt, sondern literarisch inszeniert, arrangiert und orchestriert.

Oft steht eine geliebte Frau für Casanova stellvertretend für einen bestimmten Fürstenhof, eine bestimmte Landschaft oder eine Region, die dem Reisenden noch unbekannt ist. Es handelt sich dabei um das für männliche Reisende 
charakteristische Rebecca-Motiv, ${ }^{19}$ das wir wiederholt auch bei unserem Venezianer konstatieren können. Oft sind es die Frauen, die ein ihm noch unbekanntes Gebiet verkörpern: Die Annäherung an diese Landschaft geht mit der Annäherung an eine schöne Unbekannte Hand in Hand. In diesem Zusammenhang erlaubt die nun folgende erotische Szenerie in ihrem gerafften Ablauf eine Reihe von Einblicken in die kulturellen, gesellschaftlichen und moralischen Kontexte der Zeit insoweit, als hier eine repräsentative Geschlechterbeziehung geknüpft und sexuell vollzogen wird, welche uns in die Lebensformen und Lebensnormen der Zeit hineinblicken lässt.

Lassen Sie mich zur Erläuterung kurz den Kontext für die nachfolgende Szenerie aus der Histoire de ma vie rekonstruieren! Der Ich-Erzähler hat gerade nicht nur das eigene Geld, sondern auch die Diamanten einer Geliebten verspielt und zugleich an den reichen Murray seine andere Geliebte, Tonina, abgetreten. Sie sehen, Frauen wurden in den phallogozentrischen Gesellschaften des 18. Jahrhunderts wie Objekte im männlichen Besitzstand betrachtet, um die man Wetten abschließen oder Tauschgeschäfte in die Wege leiten konnte. Das Schicksal hält freilich nur wenige Zeilen später einen Trost für den momentan glücklosen Venezianer bereit - und zwar in der reizenden Gestalt von Toninas jüngerer Schwester Barberina, die sich dem Venezianer ganz bewusst als jenem Manne nähert, der sie von ihrer Jungfernschaft befreien soll. Dann folgt die kurze, gedrängte Szene. Barberina bittet überdies ihren Geliebten vor der Einwilligung, danach ihrer Schwester Tonina davon $\mathrm{zu}$ berichten und $\mathrm{zu}$ bestätigen, dass sie zuvor noch Jungfrau gewesen sei. Der Ich-Erzähler - längst in Liebesdingen wie in Liebesdiensten sehr erfahren - willigt leichten Herzens ein und hat das Folgende zu berichten:

Nach dieser Einleitung frühstückten wir; dann legten wir uns in vollkommenem Einverständnis ins Bett und hatten eher den Eindruck, Hymen zu opfern als Amor.

Das Fest war für Barberina neu, und ihre Wonnen, ihre unreifen Ideen, die sie mir mit der größten Naivität mitteilte, und ihre von reizender Unerfahrenheit gewürzte Hingabe überraschten mich, weil ich selbst alles neu fand. Ich glaubte, eine Frucht zu genießen, deren Süße ich in der Vergangenheit noch nie so vollkommen genossen hatte. Barberina schämte sich, mir einzugestehen, daß ich ihr weh getan hatte, und das gleiche Bedürfnis nach Verstellung spornte sie dazu an, mir in jeder Hinsicht zu beweisen, daß sie größere Lust empfand, als es wirklich der Fall war. Sie war noch kein ausgewachsenes Mädchen, und die Rosen ihres knospenden Busens waren noch nicht erblüht; voll entwickelt war sie nur in ihrem jungen Kopf.

19 Zum Rebecca-Motiv vgl. den ersten Band der Reihe „Aula“ in Ette, Ottmar: ReiseSchreiben, insb. S. 187. 
Wir standen zum Mittagessen auf; dann legten wir uns erneut ins Bett und blieben darin bis zum Abend. Laura fand uns bei ihrer Rückkehr angezogen und zufrieden. Ich schenkte der hübschen Barberina zwanzig Zechinen und verließ sie mit dem Versprechen meiner ewigen Liebe, sicherlich ohne jede Absicht, sie zu täuschen; aber was das Schicksal für mich bereithielt, ließ sich schlecht mit solchen Plänen vereinen. ${ }^{20}$

Hymen, nicht Amor: Wir wohnen der Szenerie einer Entjungferung bei, in welcher der Mann auf den ersten Blick nur ausführendes Instrument ist, das auf Geheiß ,arbeitet'! Der Ich-Erzähler vollzieht folglich aus eigener Sicht zunächst einen Liebesdienst, welcher vom Mädchen angeordnet wurde. Doch dieser erweist sich rasch für ihn als höchst genussreich, und so kann er dieser Liebesszene, die uns Heutige an Nabokovs Lolita erinnert, sehr viel abgewinnen. Die Formel über die Liebe, die das Ende dieser Passage schmückt, scheint aus dem Herzen gesprochen, wiederholt sich in der Histoire de ma vie aber mehrfach und kann daher als formelhaft gelten.

Denn der Handelsreisende in Sachen Liebe lässt sich in keinem Falle von Liebesschwüren und den Versprechen unverbrüchlicher Treue aufhalten - zu sehr ist er seinem Nomadismus und der ewigen Wanderung verpflichtet. Casanova ist ein Stadtnomade, und sein Lebenszentrum ist ein immer wieder wechselndes Bett, in dem im Sinne Roland Barthes' nur die Proxemie, das mit Händen Greifbare, und die Isorhythmie, der rhythmische Gleichklang der Körper, zählen. ${ }^{21}$ Casanova portraitiert sich in dieser Szene freilich als ein dem Willen der jungen Frau unterworfenes Organ: Hierin kommt ein gewisser Fatalismus zum Ausdruck, da er sich den ihn betreffenden Wendungen des Schicksals jeweils getreu zu unterwerfen vorgibt. Dass dies mit einem Bewegungsmuster zu tun hat, das im 18. Jahrhundert von Denis Diderot in seinem Jacques le fataliste et son maître künstlerisch entwickelt worden war, hatte ich bereits ausführlich entwickelt. Giacomo Casanova erscheint in solchen Szenen als der wahre Jacques le fataliste der Liebe.

Im obigen Zitat wird die eigentliche Szene der Entjungferung in einer knappen, von topischen Metaphern nur vordergründig beleuchteten und ausgeschmückten Sprache gleichsam mit einem klinisch-sezierenden Blick behandelt.

20 Casanova, Giacomo: Geschichte meines Lebens, Bd. 4, S. 199.

$21 \mathrm{Vgl}$. zu diesen Begriffen Barthes, Roland: Comment vivre ensemble. Simulations romanesques de quelques espaces quotidiens. Notes de cours et de séminaires au Collège de France, 1976-1977. Texte établi, annoté et présenté par Claude Coste. Paris: Seuil - IMEC 2002; sowie das zweite Kapitel in Ette, Ottmar: ZusammenLebensWissen. List, Last und Lust literarischer Konvivenz im globalen Maßstab (ÜberLebenswissen III). Berlin: Kulturverlag Kadmos 2010; sowie (ders.): Konvivenz. Literatur und Leben nach dem Paradies. Berlin: Kulturverlag Kadmos 2012. 
Der Ich-Erzähler verhält sich zunächst wie in einer Versuchsanordnung. Doch der Übergang vom „observer“ zum „participant“ ist rasch und fließend - freilich ohne die auch sprachlich präzisen Qualitäten als Beobachter gänzlich zu tilgen. Wir haben bereits festgehalten, dass es sich aus heutiger Sicht um Beischlaf mit Minderjährigen handelt, dass wir diesen nach heutigem Urteil gültigen Straftatbestand aber nicht auf das Jahrhundert der Aufklärung übertragen dürfen, da es einen derartigen juristischen Tatbestand noch nicht gab. Die gesamte Szenerie wechselt zügig von der kalkulierten Versuchsanordnung zu einer wahren Liebesszene, in welcher sich Körper und Leib, Körper-Haben und Leib-Sein bei beiden Liebespartnern lustvoll durchdringen.

Halten wir an dieser Stelle noch einmal fest, dass die Initiative für diesen Akt - wie so häufig bei Casanova - von der weiblichen Partnerin ausgeht, die in Liebesdingen noch nicht so erfahren ist! Diese aktive Rolle, die Casanova den Frauen nicht immer, aber doch recht häufig zuweist, ist aufschlussreich. Denn oft sind es die Frauen, welche die latente Liebesbereitschaft des Venezianers abrufen. Man kann an dieser Stelle eine Parallele zur ersten Liebeserfahrung des Venezianers ziehen, insofern die etwas ältere Bettina doch ebenfalls die Initiative ergriffen und einen noch unerfahrenen Jungen namens Giacomo Casanova gleichsam initiiert hatte. Wie einstmals Bettina, so ergreift auch Barberina die Liebe beim männlichen Schopf. Was sich danach zwischen beiden abspielt, hat etwas geradezu Maschinenhaftes an sich: Die Mechanik der Liebe wird routiniert in Gang gesetzt. Dies bietet dem männlichen Ich-Erzähler die Gelegenheit, seinen klinischen Blick auf die Ereignisse zu werfen und die Liebesäußerungen seiner noch jugendlichen Partnerin kritisch zu analysieren. Wir haben es hier nicht mit erotischer Prahlerei, sondern mit einer Nahaufnahme aus der „vie intime“ des Aufklärungszeitalters zu tun.

Der Ich-Erzähler brüstet sich in dieser Szenerie gegenüber dem Lesepublikum nicht etwa mit seinen männlichen Wundertaten, sondern hält den Schmerz und das Bemühen des Mädchens fest, sich der Situation gewachsen zu zeigen und Lust vorzutäuschen, wo Schmerz vorherrscht. Er beobachtet dabei genau das Verhältnis von Körper-Haben und Leib-Sein bei seiner Partnerin und versucht, bei ihrem leiblichen Empfinden die Relation von Schmerz und Lust zu analysieren. Denn beide Komponenten sind bei der Jugendlichen vereint, bildet die Entjungferung doch eine Durchdringung beider Wahrnehmungsbereiche des intensiven Leib-Seins. Der vom Ich-Erzähler vollzogene Blickwechsel, mit den Augen seiner Partnerin die Liebesszene zu betrachten, führt ihn zugleich tiefer in das Liebesgeschehen hinein, ist auch er doch nun in der Lage, höchste Lust zu empfinden und die Szenerie körperlich, aber zweifellos auch intellektuell zu genießen. 
Die bereits besprochenen Liebesschwüre des Ich-Erzählers werden aus einer gleichsam gedoppelten Perspektive, jener des erzählten Ich und jener anderen, korrigierenden des erzählenden Ich dargestellt. Aus dieser Doppelperspektive entsteht eine Spannung, welche zwischen der Situation selbst und ihrer weiteren Verarbeitung unterscheidet und zugleich bekräftigt, dass es das erlebende Ich sehr wohl sehr ernst mit seinen Schwüren gemeint habe. Zugleich durchschaut das männliche Ich das Verhalten des unerfahrenen, aber liebeshungrigen Mädchens. Die Stratageme der noch nicht in ihrem Körper, aber sehr wohl in ihrem Kopf entwickelten jungen Frau werden der männlichen Sezierkunst zugänglich gemacht - und es bleibt offen, woher das Mädchen seine Vorstellungen von der Liebe bezog. Hatte sie Zugang zur erotischen Literatur ihrer Zeit, bei der die weibliche Leserschaft einen hohen Anteil ausmachte? Oder hatte sie von der Liebe detailliert von ihrer erfahreneren Schwester gehört?

Denn es könnte sehr wohl sein, dass sich die Liebessehnsüchte und Liebeswünsche bei der Lektüre zeitgenössischer Liebesliteratur gebildet hatten. Wir lernen Liebe so, wie wir Lesen, Schreiben oder Rechnen lernen - und dies jeweils kulturabhängig. Der Kontrast zwischen Körper und Kopf scheint ein wenig auf erlesene Liebesvorstellungen hinzudeuten. Auch hierin ergibt sich eine gewisse Parallele zwischen der Barberina und Bettina, der so viele künftige Liebessituationen des Ich-Erzählers prägenden Ur-Liebespartnerin, mit der wir uns bereits in unserer Vorlesung über LiebeLesen beschäftigt haben ${ }^{22}$ und auf die ich daher nicht zurückkommen will.

Zweifellos ist der analytische, bisweilen sezierende Blick des Venezianers trotz aller versuchten Blickwechsel ein zutiefst männlicher. Die Barberina erscheint als ,süße Frucht‘, die das männliche Ich lustvoll genießt. Sie wird damit als Frau zugleich objektiviert, folglich in einen Gegenstand verwandelt, sowie naturalisiert, wird zu einem Stück Natur, das sich dem männlichen Blick und Biss darbietet. Wir stoßen an dieser Stelle auf eine Art Naturgeschichte der Frau im männlichen Bewusstsein; eine Geschichte, welche aus Sicht der Männer die Frau in den Bereich der Natur rückt, mit welcher sie die Zyklen teilt, die ihren Körper prägen.

Im traditionellen patriarchalisch-männlichen Blick ist die Sexualität der Frau naturverhaftet. In dieser gleichsam philosophischen Naturgeschichte der Frau wird alles an ihr in Natur verwandelt, werden all ihre Attribute naturalisiert und damit zugleich auch die Voraussetzungen dafür geschaffen, dass sich der Mann dieses natürlichen Objekts bedienen und bemächtigen kann. Nicht umsonst waren wir zuvor bereits auf viele naturalisierende Hinweise in Casano-

22 Vgl. den zweiten Band der „Aula“-Reihe in Ette, Ottmar: LiebeLesen, S. $304 \mathrm{ff}$. 
vas Histoire de ma vie gestoßen. Sie ziehen sich komplett durch die Erinnerungen des Venezianers.

Die ,Natürlichkeit‘ des Mädchens hält noch zusätzliche Freuden für den Ich-Erzähler bereit. Barberinas Hingabe wird zum Beispiel mit einer gehörigen Dosis Unerfahrenheit gewürzt, welche beim Ich-Erzähler deutlich neue Erfahrungshorizonte eröffnet, da er es gewöhnlich mit erotisch wie sexuell längst sehr erfahrenen Frauen zu tun hat. Das Lust-Objekt Frau besitzt gleichsam eine ,Natürlichkeit', die es für den Mann nur noch appetitlicher und wohlschmeckender macht: Die Frau wird in ein Objekt verwandelt. Wir sehen hier in aller Deutlichkeit, wie und auf welcher Grundlage patriarchalisch bestimmte Vorstellungen die Geschlechterdifferenz bestimmen oder zumindest prägen.

Das erzählte Ich ist um einen Blickwechsel bemüht. Doch an dieser Stelle erscheint die Frau oder das Mädchen nur als Gegenstand im Blick des Mannes, so verständnisvoll sich dieser in der Szenerie auch geben mag. Sie wird zugleich objektiviert, naturalisiert und distanziert - und in diesem Zusammenhang mag am Ende auch das Geld stehen, das gleichsam als letzter Abschiedsgruß des IchErzählers und als Entgelt für die kostenlosen Liebesschwüre gelten kann. Denn mit der Bezahlung für die Liebe distanziert sich der Mann von der affektiven, emotionalen Seite der Liebesbeziehung und lässt alleine noch die zeitweise Verschränkung der Körper ineinander gelten. Mit dem Geld wird Liebe abgegolten: Es entlohnt die zeitweise Zur-Verfügung-Stellung des weiblichen Körpers für die männliche Lust.

Die Barberina steht stellvertretend für den Typus des unschuldigen Mädchens, dessen Verbindung mit der Natürlichkeit der Frau und damit deren Objektivierung als Gegenstand wir bereits gesehen haben. Zugleich verkörpert sie aber auch den Topos der Zufallsbekanntschaft, des von Beginn an erotisch aufgeladenen Zusammentreffens mit einer schönen Unbekannten an einem dem Durchreisenden unbekannten Ort. Wir erkennen hier nicht allein die Identifizierung der unbekannten Schönen mit einer Stadt, mit einem Dorf oder einem Landstrich, sondern auch die Liebe erzeugende Macht des „hasard“, welche die Zufallsbekanntschaft so stark erotisch auflädt. Wir stoßen an dieser Stelle auf ein berühmtes literarisches Motiv, das Charles Baudelaire in seinem berühmten Gedicht $A$ une passante aus seinen Fleurs du mal auf die Großstadt und die zwar mögliche, aber nicht realisierte Liebe beziehen wird. Bei Casanova hingegen ist der Zufall Prinzip - ganz so wie bei dem Fatalisten Jacques: Beide nehmen die jeweiligen Gelegenheiten wann immer möglich wahr.

So wird bei Casanova dieses Motiv der Zufallsbekanntschaft sehr häufig von einer kurzen, aber heftigen Liebesbeziehung gekrönt. Gerade diese Gelegenheiten sind es, denen der Italiener stets mit allen Sinnen verfällt. Man könnte nach der Lektüre der Histoire de ma vie mit guten Gründen sagen: Gele- 
genheit macht Liebe. In eben diesem Sinne handelt der Ich-Erzähler in den verschiedenen Liebesepisoden seines Lebens, stets in latenter Liebesbereitschaft bei sich bietender Gelegenheit, mit schönen unbekannten Frauen ein Schäferstündchen zu verbringen. Dabei ist die Quantität in sich kein Ziel, wird aber durchaus im Tagebuch vermerkt und gelangt auch in die Aufzählungen und Listen, die in der Geschichte meines Lebens narrative Gestalt annehmen. Denn Casanova ist nicht nur passionierter Sammler, er erstellt auch Listen, wird von einer Liebschaft in die nächste getrieben und führt darüber Buch.

Die Barberina hat uns einen Vorgeschmack gegeben: Die Liebe und die Liebesbeziehungen sind hinsichtlich ihrer Diskursivität in starkem Maße von der Literatur geprägt. Dies ist insbesondere bei den Frauen der Fall. Die Barberina hat uns hier nur die Richtung gewiesen, die das 19. Jahrhundert befolgen wird: Flauberts Emma Bovary wird den Typus der Frau verkörpern, welche ihre Vorstellungen von der wahren Liebe aus den romantischen Romanen des frühen 19. Jahrhunderts bezog. In Casanovas Geschichte meines Lebens erweist sich die Position und Problematik des „Libertinage“ im 18. Jahrhundert als eine auf einer grundlegenden Geschlechterungleichheit beruhende Beziehung - zumindest tendenziell ganz so, wie wir dies abschließend noch beim Marquis de Sade werden beobachten können. Die Gymnastik der Liebe jedenfalls - hier am Beispiel des 18. Jahrhunderts - kann nicht als Beleg für die Gleichheit der Geschlechter gelten, sondern ist eine Begegnung zwar auf gleicher Augen- und Mund-Höhe, aber doch in einer klaren Asymmetrie der Liebespartnerinnen und Liebespartner. Darüber sollten wir uns nicht hinwegtäuschen! Denn wir bewegen uns innerhalb der phallogozentrisch geprägten Atmosphäre der Gesellschaften der Aufklärung zwischen zwei Welten.

Die Liebe, so könnte man formulieren, erscheint nicht in erster Linie als Realisierung einer Zweierbeziehung, sondern als eine Art Figurenfeld, als ein Netzwerk verschiedener möglicher Konfigurationen, das sich gerade nicht auf eine heterosexuelle Zweierbeziehung reduzieren lässt. In Giacomo Casanovas Histoire de ma vie werden die verschiedenartigsten Figuren der Liebe vorgeführt und mit bestimmten prägenden Grundmustern in Beziehung gesetzt. Wir haben es also mit einer relationalen Logik zu tun, die als Versuchsanordnung in Serie geschaltet ist, wenn wir im Sinne des Venezianers von der Liebe sprechen. Derartige Vorstellungen ließen sich - wie wir noch sehen werden - im 18. Jahrhundert auch bei anderen Autoren herausdestillieren; allen voran beim „göttlichen Marquis“, beim Marquis de Sade, bei dem freilich die tendenziell unendliche Reihe der Liebespartnerinnen absichtsvoll begrenzt wird.

Gegen Ende unseres Durchgangs durch die autobiographisierenden Memoiren des Giacomo Casanova sei nicht verschwiegen, dass er auf seinen Reisen nicht nur Höhen, sondern auch Tiefen durchzumachen hatte. So kam er nach 
einer Reihe von Enttäuschungen in die Nähe eines Selbstmordes. Nur ein Zufall, so erläutert er, habe ihn davon entfernt, und nur eine Frau, deren Zuneigung er verspürt, konnten ihn wieder ins Leben zurückholen und in eine dem Leben und der Liebe wieder zugewandte Person verwandeln. Wie später bei Honoré de Balzac und dessen Romanwelt bildet der Zufall das entscheidende Moment, ist der „hasard“ der „plus grand romancier du monde“. Dass er wenig später seine Liebesbezeugungen mit einer schönen Sarah austauschte, die daraufhin in eine ähnliche Zuneigung, aber zugleich in tiefe Ohnmacht verfiel, gehört zu den für den Ich-Erzähler weniger angenehmen Erlebnissen wollte er doch, wie er in seinen Memoiren betonte, um nichts in der Welt den Schwächezustand der jungen Dame zur Befriedigung seiner Bedürfnisse nutzen.

Wenn sich Casanova - zumindest nach eigener Einschätzung - hier ganz als Ritter und edler Vertreter seines Geschlechts erwies, so rumorte es doch in ihm, in dieser Situation nicht auf seine Kosten gekommen zu sein. Seine Formel dafür ist einfach: „Um Sarah zu vergessen, hatte ich eine andere Sarah nötig.“23 Und in der Tat sollten sich recht bald wieder andere Liebschaften einstellen, von denen der Ich-Erzähler zu berichten weiß.

Allerdings gelangen wir an dieser Stelle erneut zum Thema der Liebe für Geld, der mehr oder minder blanken Prostitution. Denn es sind Liebschaften der berechnenden Art, die sich dem Manne eröffnen, der doch um seiner selbst geliebt werden will. Der Ich-Erzähler, der sich längst als „Libertin“ zu erkennen gegeben hat, will endlich auf seine Kosten kommen und lässt es auch gegenüber einer jungen Schönen nicht an Beredsamkeit und Angeboten mangeln, um im Gegenzug eine Liebesnacht mit der jungen Dame verbringen zu können. Sehen wir uns diese Zweierbeziehung einmal näher an, denn sie sagt uns viel über die Liebeskonzeption des italienischen Verführers:

„Was werden Sie für uns tun“, fragte sie, „wenn ich die Nacht mit Ihnen verbringe?“

„Ich werde Ihnen zwanzig Guineen geben, ich werde sie auch alle unterbringen und verköstigen, solange sie nett zu mir sind.“

Ohne jede Antwort begann sie, sich auszuziehen, und kam in meine Arme, nachdem sie mich vergeblich gebeten hatte, die Kerzen auszulöschen. Ich fand nur Fügsamkeit. Sie ließ mich gewähren, das war alles; sie beehrte mich nicht mit einem einzigen Kuß. Das Fest dauerte eine Viertelstunde. Meine einzige Hilfe war die Vorstellung, ich hielte Sarah in meinen Armen. Beim verliebten Zusammensein ist die Illusion eine Grundvoraussetzung. Ihre herzlose Stumpfheit ärgerte mich derart, daß ich aufstand, ihr eine Zwanzigpfundnote gab und sagte, sie solle sich anziehen und in ihr Zimmer hinaufgehen.

23 Casanova, Giacomo: Geschichte meines Lebens, Bd. 9, S. 420. 
„Morgen früh werden Sie alle das Haus verlassen“, fügte ich hinzu, „denn ich bin mit Ihnen nicht zufrieden. Statt sich der Liebe zu überlassen, haben Sie sich prostituiert. Schämen Sie sich!“

Sie zog sich an und entfernte sich wortlos; ich schlief sehr verdrossen ein. ${ }^{24}$

Wir wohnen hier einer Bankrotterklärung der Liebe in ihrem körperlichen Vollzug bei. Sie ist in dieser ,Liebesbeziehung' zur reinen Mechanik, zur reinen Gymnastik verkommen, die nur vollzogen werden kann, wenn an die Stelle des benutzten Liebesobjekts ein anderer Körper, ein anderes geliebtes Wesen gedacht und imaginiert werden kann. Lassen Sie uns unsere Beschäftigung mit den Liebesbeziehungen Giacomo Casanovas also mit einer Szene beenden, die zwar einen vollzogenen Beischlaf, aber keinerlei Befriedigung oder gar Erfüllung des Liebesbegehrens beinhaltete! Die Bezahlung der Liebesmühen ist nichts anderes als die Unterschrift unter die Bankrotterklärung der Liebe.

Doch was ist das für eine Szene! Das gesamte ,Fest', also die Liebesvereinigung, wird herzlos durchgeführt und entspricht damit in keiner Weise den Liebesvorstellungen des Venezianers. Auch wenn Casanovas Erzählerfigur durchaus von Zeit zu Zeit der Prostitution nicht abhold ist, so dürfen seine Liebesbeziehungen nicht nach ihr riechen. Die Fügsamkeit einer Frau kommt einer Unterwerfung unter den Willen des Mannes gleich - doch diese Unterwerfung muss nach Ansicht des Venezianers aus Liebe, aus freiem Willen und nicht aus finanziellen oder anderen utilitaristischen Erwägungen erfolgen. Nicht umsonst sind es bei Casanova häufig die Frauen, welche die Initiative ergreifen. Und wie bei der ersten Liebelei und Liebesbeziehung ist das erzählte Ich ein bevorzugter und geherzter Gegenstand einer weiblichen Liebe, die alle Sinne des erzählten Ich befriedigt.

Dennoch ist in dieser Szene eine kleine Bemerkung, eine eher marginale Beobachtung von großem Gewicht, welche der Ich-Erzähler gleichsam als Mittel seiner Erregung einsetzt. Denn er stellt sich während des Geschlechtsaktes vor, seine geliebte Sarah in den Armen zu halten und die Nacht mit ihr zu verbringen. Für den Ich-Erzähler ist also die Illusion, mit anderen Worten die Fiktion, eine „Grundvoraussetzung“ für „verliebtes Zusammensein“, das weit über den Vollzug des Geschlechtsakts hinausgeht. Es ist diese Illusion, dieses illusionäre und letztlich fiktionale Element, das die Flachheit der ewig wiederholten Positionen und Stellungen, der reinen Physis und Mechanik der Liebe, zu überbrücken versteht. So erst kann sich in der Geschichte meines Lebens eine Liebe einstellen, welche das männliche Ich immer wieder von neuem begehrt.

24 Ebda., Bd. 10, S. $17 \mathrm{f}$. 
Wir gelangen an diesem Punkt an die Grenzen der Liebe im Verständnis Giacomo Casanovas. Denn längst ist die oben beschriebene Liebes-Mechanik bei unserem Libertin heiß gelaufen und hat sich immer mehr ermüdet. So stellen sich nun Gedanken an Selbstmord ein, welche ein Weiter-Leben des Ich in Frage stellen. Lassen Sie mich abschließend noch diese bei Giacomo Casanova eigentlich kaum zu erwartenden Gedanken an den Freitod einblenden, zeigen sie doch auf, wie sehr die Quantität, wie sehr die rein physische Liebe den Venezianer auch mental ermüdet hat! Dabei wird ein weiteres Mal die Leserschaft als Zeuge angerufen:

Der Leser kann mir glauben, daß alle, die sich wegen eines großen Kummers umgebracht haben, damit dem Wahnsinn zuvorgekommen sind, der sich ihres Verstandes bemächtigt hätte, wenn sie es nicht getan hätten, und daß daher alle, die verrückt geworden sind, dieses Unglück nur durch Selbstmord hätten verhindern können. Ich habe diesen Entschluß erst gefaßt, als ich daran war, den Verstand zu verlieren, wenn ich noch einen einzigen Tag gezögert hätte. Daraus ergibt sich: Der Mensch darf nie Selbstmord begehen, denn es kann der Fall eintreten, daß sein Kummer schwindet, bevor ihn der Wahnsinn befällt. Mit anderen Worten, wer stark genug ist, nie zu verzweifeln, ist glücklich. Ich war nicht stark genug, ich hatte alle Hoffnung verloren und wollte mich mit Vorbedacht umbringen. ${ }^{25}$

Suizid und Wahnsinn könnten am Ende jener Versuchsanordnung stehen, mit welcher Casanova die Liebe als ein mit unendlich vielen Liebespartnerinnen stets von Neuem aufzuführendes Liebesspiel konzipiert. Seine Gedanken an Selbstmord stehen in Relation mit seinen Gefühlen, letztlich an Wahnsinn zu erkranken und zuvor seinem Leben eigenhändig ein Ende bereiten zu müssen. Es ist eine unglückliche Seite an ihm, dem großen Frauenverführer, welche sich nicht im herkömmlichen Bild des Italieners findet, aber doch zu seiner psychischen Ausstattung gehört. Denn der Libertin, der stets vorgibt, seine Gefühle im Griff zu haben, läuft in einer nach Jahrzehnten der Irrfahrten schwierigen Phase Gefahr, seinen Rhythmus und seinen Weg, der ein ständiges Hin- und herspringen ist, zu verlieren. Die ständig neu ausgetauschten Liebespartnerinnen, die von ihm selbst gewählte Versuchsanordnung einer letztlich unabschließbaren Serie von ,Objekten“ verwirren den Libertin und nähern ihn dem Wahnsinn an. Doch Casanova kann sich wieder fangen und setzt mit verstärktem Elan seine Suche nach persönlichem Glück mit neuerlichen Reiseabenteuern, aber auch mit vielen gleichsam seriellen Liebesabenteuern in den unterschiedlichsten europäischen Ländern fort. Seine Suche nach Liebe ist eine rastlose Suche nach Erkenntnis.

25 Ebda., Bd. 9, S. 376. 
Hatte Roland Barthes in seinen Fragments d'un discours amoureux achtzig unterschiedliche Figuren aufgelistet, ${ }^{26}$ so sind die einhundertsechzehn Frauen und Mädchen, welche in Casanovas Histoire de ma vie hautnah auftauchen, in gewisser Weise die Selbsterkundungen eines Ich, das sich letztlich doch - wie der alte Bibliothekar auf Schloss Dux - in absoluter Einsamkeit wiederfindet. Casanovas Schriften darf man nicht nur als Lebenswissen im Sinne eines Wissens von der Erotik, sondern mehr noch als einen Vorstoß hin zu einer Erotik des Wissens interpretieren.

Unser Durchgang durch diese Erotik des Wissens wäre nicht vollständig, würden wir an dieser Stelle nicht von einem Autor sprechen, der auf höchst bewusste Weise Versuchsanordnungen körperlicher Liebe entwarf, die seinen Namen im gesamten 19. Jahrhundert und während der ersten Jahrzehnte des 20. Jahrhunderts in den Dunstkreis des Perversen und Pathologischen stellten. Ich spreche vom Marquis de Sade, vom „Göttlichen Marquis“, wie er auch genannt wurde, dessen Werke im Übrigen im 19. und 20. Jahrhundert stets in allen Giftschränkchen der Schriftsteller zu finden waren. Heute ist dies nicht mehr der Fall, sind sie doch längst seit den sechziger Jahren nicht zuletzt auf Grund der Studien eines Roland Barthes kanonisiert und in den Schulunterricht in Frankreich aufgenommen. Gerade der Sade geschickt in den Verbund dreier Schriftsteller aufnehmende Band Sade, Fourier, Loyola von Roland Barthes ${ }^{27}$ hat viel zur Normalisation Sades beigetragen. ${ }^{28}$

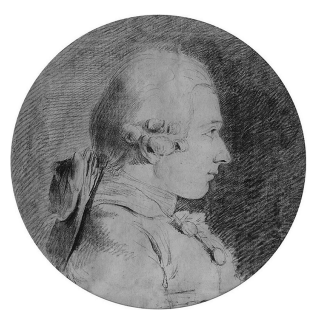

Abb. 43: Charles-Amédée-Philippe van Loo: Angebliches Porträt von Donatien Alphonse François de Sade (1740-1814).

Sicherlich hat man die Edition von Sades Werken entschärft, indem man ihnen einen umfangreichen Apparat etwa an unterschiedlichen Paratexten beigab, welchen das geneigte Lesepublikum erst zu durchqueren hatte, bevor es zum eigentlichen Schreiben vorstoßen konnte. So ist, um ein Beispiel zu nennen,

26 Eine Deutung von Casanova im Lichte der Barthes'schen Figuren der Liebe unternehme ich in meiner Vorlesung über LiebeLesen, S. 286-315.

27 Vgl. Barthes, Roland: Sade, Fourier, Loyola. Paris: Seuil 1971.

28 Vgl. auch Lely, Gilbert: Sade. Etudes sur sa vie et sur son œuvre. Paris: Gallimard 1967. 
die in den sechziger Jahren des 20. Jahrhunderts in Frankreich erschienene Ausgabe der Euvres Complètes des Marquis stets mit Vorworten gepflastert. Die Edition von Les 120 Journées de Sodome - das 1975 dank der Verfilmung durch Pier Paolo Pasolini im kollektiven (und visuellen) Gedächtnis des Westens gehalten wurde - etwa besitzt nicht weniger als fünf Vorworte und ein „Avertissement": fürsorgliche Paratexte, in denen unter anderem ein Psychiater, aber auch der Philosoph Pierre Klossowski zu Wort kommen und den Weg zu diesem einstmals verruchten Text ebnen.

Dennoch haftet dem Divin Marquis auch noch in Deutschland zu Unrecht ein anrüchiges Bild an, von dem sich der französische Schriftsteller wohl erst in einem weiteren Jahrhundert befreien können wird. Da ich bei unserer Vorlesung über LiebeLesen schon einmal auf Casanova und den Marquis de Sade kurz einging und dabei die Erfahrung machen musste, dass es auch bei den Studierenden Gruppen gibt, die sich massiv gegen die literaturwissenschaftliche Lektüre derartiger Texte zur Wehr setzen, möchte ich an dieser Stelle alles vermeiden, was Sie an den Rand des Entsetzens führen könnte. Für Ihre eigenen Lektüren sind ja nur Sie selbst verantwortlich!

Dass sich das literarische Schreiben von Donatien Alphonse François, Comte de Sade, der am 2. Juni 1740 in Paris geboren wurde und am 2. Dezember 1814 aus dieser Welt schied, sehr viel mit den gesellschaftlichen und politischen Dimensionen des europäischen Aufklärungszeitalters zu tun hat, mag seine Einführung in Les 120 Jours de Sodome zeigen:

Die beträchtlichen Kriege, welche Ludwig XIV. während des Verlaufs seiner Herrschaft zu führen hatte, erschöpften die Staatsfinanzen und die Möglichkeiten des kleinen Volkes, eröffneten gleichwohl aber das Geheimnis, eine enorme Menge an Blutsaugern zu bereichern, welche sich stets der öffentlichen Kalamitäten bedienen, die sie entstehen lassen, anstatt sie einzudämmen, und dies, um daraus alsbald nur um so größeren Profit zu ziehen. Das Ende dieser im Übrigen so sublimen Herrschaft stellt vielleicht eine der Epochen des französischen Reiches dar, in denen man die meisten dieser obskuren Reichtümer sehen konnte, welche allein durch Luxus und ebenso dumpfe Ausschweifungen wie sie selbst zerplatzen. Es war gegen Ende dieser Herrschaft und kurz bevor der Regent versuchte, vermittels des berühmten Tribunals, das man unter dem Namen der Justizkammer kennt, jene Unmenge an Halsabschneidern zur Kasse zu bitten, dass sich vier von ihnen jene einzigartigen Ausschweifungen vorstellten, von denen wir in der Folge zu berichten haben werden.

Es geschähe zu Unrecht, stellte man sich vor, dass sich allein der Bürgerstand mit diesem schändlichen Treiben beschäftigte; denn an dessen Haupte wusste man von sehr hohen Herren. Der Herzog von Blangis und sein Bruder, der Bischof von ... , die alle beide hierbei immense Reichtümer aufgehäuft hatten, stehen als unhinterfragbare Zeugen dafür ein, dass der Adel nicht anders als die anderen die Mittel keineswegs vernachlässigte, sich auf solchem Wege zu bereichern. Diese beiden illustren Persönlichkeiten, die durch gemeinsame Lüste und Affären intim verbunden waren mit dem berühmten Durcet und dem 
Präsidenten von Curval, waren die ersten, die sich die Ausschweifungen vorstellten, deren Geschichte wir niederschreiben, und als man diese Pläne den beiden Freunden mitteilte, machten sich alle vier daran, die Akteure dieser berühmten Orgien zusammenzustellen. ${ }^{29}$

Donatien Alphonse François de Sade entwarf für die Darstellung der Orgien und sexuellen Praktiken stets eine gesellschaftliche Kontextualisierung, welche die dargestellten Ausschweifungen körperlicher Liebe und Befriedigung als einen Teil ihrer Epoche erscheinen ließ. Es gibt folglich hierarchische und finanzielle Hintergründe für all jene Geschichten, die in der Folge detailliert beschrieben werden. Wenn wir also in den 120 Tagen von Sodom eine Versuchsanordnung erkennen können, die Züge eines Zwangslagers, ja vielleicht eines Konzentrationslagers vorwegnimmt und auf eine extreme Beherrschung insbesondere weiblicher Körper abzielt, so wird dies stets gesellschaftlich situiert und als Phänomen einer Epoche verstanden, die keineswegs weit außerhalb der Aufklärung - und vor allem der mit Max Horkheimer und Theodor W. Adorno verstandenen Dialektik der Aufklärung - steht. Um unser Bild vom 18. Jahrhundert abzurunden, müssen die Schriften des Marquis de Sade unbedingt mithinzugezogen werden, um nicht nur die ,emanzipatorischen' Dimensionen der Aufklärung zu sehen. Denn es gab in eben dieser Epoche - wie wir sahen - eine starke ,Modernisierung` kolonialer Abhängigkeitsverhältnisse während der zweiten Phase beschleunigter Globalisierung, in welcher wir uns auch bei diesem Schriftsteller und seinen Texten befinden.

Vor allem sollten wir nicht vergessen, dass es derartige Formen absoluter Herrschaft waren, die gerade auch in den Kolonien zur Anwendung kamen und am Ausgang des 19. Jahrhunderts jene Formen von „Concentration Camps“ entwickelten, wie sie die Briten in Südafrika oder auch die Spanier in Kuba zur Anwendung brachten. Mit der oben zitierten Passage treten wir ein in das mehrfach wiederholte „imaginer“, in die Vorstellungen und Bilderwelten, welche die totale Herrschaft über die Körper anstrebten, wie sie zum damaligen Zeitpunkt insbesondere auf den Zuckerrohrplantagen von Saint-Domingue herrschten. Dass die einst reichste Kolonie der Welt unglaubliche Profite und einen fabelhaften Luxus für das eingesetzte französische Kapital erwirtschaftete - und ich benutze hier bewusst zentrale Lexeme des Sade'schen Textes -, mag die andere Seite der obigen gesellschaftlichen Kontextualisierung darstellen und auch manche der „débauches“, der Ausschweifungen erklären, die mit der Kolonialherrschaft europäischer Mächte immer einhergingen.

29 Sade, Donatien Alphonse François de: Les 120 Journées de Sodome, ou l'École du libertinage. Texte établi par Eugène Dühren. Paris: Club des Bibliophiles 1904, S. 1. 
Es scheint mir daher wichtig, ja sogar entscheidend, die Beherrschung der Körper als deren Kolonisierung zu begreifen - und nicht umsonst spricht man etwa auch von ,Sexsklaven', die ihren Herren ebenso sehr ausgeliefert sind wie die Arbeitssklaven ihren Sklavenbesitzern. Denn was uns vorgeführt wird, ist stets weniger der irrationale Abgrund eines feudalistischen Zeitalters, als vielmehr die Durchrationalisierung der Benutzung von Körpern, welche als willfährig gemachte Objekte - wie Roland Barthes in seinen Studien zu Sade gezeigt hat - möglichst zahlreichen Verwendungen, Stellungen und Positionen zugeführt werden können. Sind darin nicht die ,Urszene، und mehr noch die Grundstrukturen kolonialer Herrschaft erkennbar? Dass diese Herrschaft innerhalb einer patriarchalischen und mehr noch phallogozentrischen Gesellschaft in den Texten des Divin Marquis über weibliche Körper ausgeübt wird, macht deutlich, dass es sich bei dieser Körper-Beherrschung um einen Kolonialismus handelt, der über die Körper der Frauen mit aller Konsequenz und menschenverachtenden Brutalität ausgeübt wird.

In meiner Vorlesung über LiebeLesen habe ich Bezüge herzustellen gesucht, die vom Don Juan Molières und damit dem französischen 17. Jahrhundert zweifache Verbindungslinien in das europäische 18. Jahrhundert bilden: zum einen zu Giacomo Casanova und zum anderen zur Figur des Marquis Sade. Wir bekommen auf diese Weise die grundlegenden Traditionslinien besser in den Griff, welche die europäischen Literaturen zweifellos durchziehen. Und es ist nun an uns, die Verführung und Beherrschung weiblicher Körper mit Bildern des Kolonialismus zusammenzudenken, wie sie diesen gesamten Zeitraum der Expansion Europas nicht nur am Rande bestimmen. Der europäische Kolonialismus ist nicht ,jenes Andere‘, das wir fein säuberlich vom eigentlichen ,Eigenen' abtrennen können oder einfach hübsch ,gesondert' betrachten dürfen. Er durchzieht die europäischen Kulturen und selbstverständlich auch Literaturen vom Beginn der Frühen Neuzeit, von der ersten Phase beschleunigter Globalisierung an, zumindest bis tief ins 19. Jahrhundert. Doch er reicht in der Fortschreibung seiner Bilderwelten ins ins 21. Jahrhundert und damit bis zu uns.

Damit sei nicht behauptet, dass sich eine direkte Linie etwa von Molières Dom Juan und so vielen anderen, niemals in diesen Zusammenhang gestellten Liebes-Texten der europäischen Frühen Neuzeit unter kolonialistischen Vorzeichen unvermittelt bis zu Casanova und Sade ziehen ließe, wohl aber, dass eine vermittelte und komplexe Filiation besteht, die in ihrer Wirkmächtigkeit keineswegs geringer ausfällt als eine direkte literarische Verbindung. Die koloniale Dialektik der Aufklärung dynamisierte auch diese Relationen im 18. Jahrhundert und führte zu literarischen Ergebnissen, die wie die Werke von Casanova oder Sade für das Aufklärungszeitalter in Europa stehen. Auch darum ist es so wichtig, sich mit den Texten Casanovas wie mit jenen des Marquis de Sade literatur- 
wissenschaftlich zu beschäftigen und diese nicht in die pathologische Ecke zu verfrachten.. Sie sind nicht ,das Andere“ einer Aufklärung zwischen zwei Welten: Sie stehen für diese Aufklärung selbst und dürfen aus ihr und ihrem umfassenden Verständnis nicht herausgebrochen werden.

Die Sade-Studien von Roland Barthes haben das Bild eines geradezu strukturalistischen Autors entworfen, der systematisch und methodisch vorging, der die Grenzen der körperlichen, objekthaften Kombinationsmöglichkeiten zu erforschen trachtete und der niemals die Wiederholung ein und derselben Liebessituation und Liebesstellung in seinen Schriften akzeptierte. ${ }^{30}$ Barthes war an der Scharnierstelle zwischen Strukturalismus und Poststrukturalismus zweifellos für diese Art von fundamentalen Einsichten prädestiniert. Sade gehörte für Barthes ebenso wie Fourier oder Loyola zu den Fundamenten abendländischer Kultur und Literatur - Er war nicht aus ihr herauszulösen! Aus dieser von Barthes analysierten Sichtweise der Beherrschung menschlicher Körper entwickelte Sade eine durchaus physisch und physiologisch gemeinte Kombinatorik der Liebe, die letztlich einige der Grundannahmen Don Juans teilt und in der „variatio“ den eigentlichen Urgrund für eine Lust erblickt, welche der Abwechslung, aber auch der ungeteilten männlichen Herrschaft bedarf. Der kolonialistische Unterton ist für uns nun leicht herauszuhören!

Im gleichen Atemzug verlagert und verdoppelt Donatien Alphonse François de Sade aber den Schwerpunkt der Leidenschaft und der im doppelten Wortsinne verstandenen Passion. Es geht nicht länger um den Prozess der strategisch vorbereiteten und geplanten Eroberung, sondern um die verschiedensten Formen der Inbesitznahme von Körpern oder - um es etwas stärker zu sagen von Körper-Objekten. Wir könnten auch sagen: Es geht um deren Kolonialisierung und damit um deren hemmungslose Ausbeutung. Denn auch dies gehört zur Dialektik der Aufklärung, wollen wir diese und mit ihr die Aufklärung selbst in einem umfassenden Sinne begreifen. Wir haben es hierbei mit einer ebenfalls schier unendlichen Abfolge von „possessions“ und Stellungen zu tun; zugleich mit einer gezielten Verlagerung des Leidens und damit der Passion in den Vollzug der Liebe und des Liebesaktes selbst. Diese Passion ist auf den Leib des Subjekts und dessen Lust gerichtet, wobei simultan - wenn auch nicht notwendig im selben Körper des Anderen - höchste Lust und höchstes Leiden sowie das Leiden an der Lust zum Vollzug und zum Höhepunkt gebracht werden. Dies, scheint mir, ist die Ökonomie der Sade’schen „imaginations“ - und diese Ökonomie ist unverkennbar eine kolonialistische!

30 Vgl. Barthes, Roland: Sade, Fourier, Loyola. Paris: Seuil 1971. 
Ich möchte Ihnen kurz einen Einblick in diese gezielte und wohlkalkulierte Kombinatorik von Stellungen anhand einer fast beliebig gewählten Passage aus Sades Justine ou les malheurs de la vertu vor Augen führen und damit zugleich das Thema Sade in unserer Auseinandersetzung mit Casanova auch schon wieder beenden. Ohne jeden Zweifel wäre es notwendig, sich wesentlich ausführlicher mit dem Marquis zu beschäftigen, doch scheint mir die akademische Gattung der Vorlesung hierfür nicht die geeignetste zu sein: Auch ein Erich Köhler fand bei seinen Heidelberger Studenten in bewegten Zeiten wenig Gegen-Liebe ...

So präsentiere ich Ihnen also die Stelle, die mir eher zufällig in die Hand gefallen ist und in der Justine von ihren Peinigern berichtet. Bitte vergessen Sie nicht, dass diese Passage auf eine noch starr feudalistische und phallogozentrische Gesellschaft des Ancien Régime gemünzt ist, welche tief in den Kolonialismus verwickelt ist und gesellschaftliche Dimensionen des 18. Jahrhunderts evoziert, wie sie für das Zeitalter der Aufklärung fundamental sind:

Der dritte hieß mich auf zwei voneinander entfernte Stühle steigen und setzte sich darunter, erregt von der Dubois, die an seinen Beinen platziert war, und er ließ mich vorbeugen, bis sein Mund sich quer zum Tempel der Natur befand; Sie könnten sich niemals vorstellen, Madame, was dieser obszöne Sterbliche zu begehren wagte; ich musste, ob nun Lust oder nicht, diese leichten Bedürfnisse befriedigen ... Gerechter Himmel! Welch depravierter Mensch kann denn auch nur einen Augenblick lang Lust bei solchen Dingen empfinden! ... Ich machte, was er wollte, ich überschwemmte ihn, und meine vollständige Unterwerfung erreichte bei diesem furchtbaren Menschen eine solche Trunkenheit, welche ohne diese Infamie nichts ausgerichtet hätte. ${ }^{31}$

Wir wohnen in dieser Passage einer Szene weiblicher Unterwerfung bei, in welcher die Frau oder besser die Frauen nichts anderes als Lustobjekte des Mannes sind, die ihrer kolonialen Ausbeutung zugeführt werden. Ich hätte diese, aber auch viele andere Passagen auswählen können, doch scheint mir diese Szene für unsere Vorlesung als besonders geeignet, da sie zwar das ist, was in den Vereinigten Staaten als „sexually explicit“ bezeichnet wird, zugleich aber nichts direkt benennt, was - so hoffe ich - bei Ihnen Anstoß erregen könnte.

Gewiss, wir sind nicht mehr im Heidelberg der sechziger Jahre, wo die Erwähnung des „Göttlichen Marquis“ durch den noch jungen Erich Köhler das Missfallen der Studierenden erregte und es Eier und Tomaten gehagelt haben soll, um die depravierte bürgerliche Literaturwissenschaft dieses allerdings linken Professors zu geißeln! Erich Köhler hat - soviel darf man sagen - unter die-

31 Sade, Donatien Alphonse François de: Justine ou les Malheurs de la vertu. En Hollande : Chez les Libraires associés. Paris: Girouard 1791, S. 54 f. 
sem Missverständnis zeit seines Lebens sehr gelitten; auch noch, als er die Universität Heidelberg geradezu fluchtartig verließ und an die Universität Freiburg wechselte, wo alles rund um die Achtundsechziger-Generation etwas ruhiger zu sein schien. So hoffe ich durchaus, Ihnen diese Passage zumuten zu können, da sie ein wichtiges Segment des Liebesbegehrens abdeckt, das nicht im Zentrum unserer Vorlesung steht, wohl aber im Kontext unserer Beschäftigung mit Giacomo Casanova und kurz auch mit dem Marquis de Sade nicht unerwähnt bleiben soll. Und ich bitte auch strafmildernd $\mathrm{zu}$ berücksichtigen, dass ich nicht verschreckt, sondern ganz planmäßig meinen Dienst als Professor an dieser Universität schon bald beenden werde; und ich möchte dies gerne tun, ohne am Ende noch Ihr Missfallen erregt zu haben oder - wie man im Elsass sagt - mit allerlei Legümen beworfen zu werden!

Was ich Ihnen an diesem Beispielstext aus der Feder Sades zeigen wollte, das ist die präzise und bewusste Kombinatorik, die der gesamten Sade'schen Lusttheorie zu Grunde liegt. Es geht folglich höchst rational zu auf diesen Seiten; und es sind gerade die unterschiedlichen Kombinatoriken dieser Mechanik der Lust, die im Mittelpunkt des Sade'schen Schreibens und seiner Imaginationen stehen. Roland Barthes hatte als französischer Literatur- und Kulturtheoretiker ein geradezu strukturalistisches Verhältnis zu Sade, dessen Szenerien ständiger Lusterzeugung er damit gleichsam die erotische Spitze nahm und einen bemerkenswerten Perspektivenwechsel in den Sade-Studien herbeiführte. Dies ist zweifellos ein Thema - die Kanonisierung Sades und dessen Überführung in einen Schulbuchautor -, das sich näher auszuführen lohnte. Doch fehlt mir die Zeit dazu in einer Vorlesung, in welcher es um die Aufklärung zwischen zwei Welten und um ein möglichst umfängliches Bild von der nicht allein europäischen Aufklärungsepoche geht.

Freilich müssen wir etwas ergänzen, das Roland Barthes geflissentlich und ganz bewusst aus seinen Studien ausblendete! Denn es kommt ein wichtiges, vielleicht das wichtigste Element noch hinzu, das ebenfalls in dieser Szene deutlich wird: die völlige Unterwerfung des Körpers der Frau, eine totale Gewalt, welche über die Körper aller Frauen ausgeübt wird und eine wichtige Grundbedingung für die Lust der Protagonisten ist. Der Raum, in welchem eine solche absolute Gewalt im 18. Jahrhundert ungestraft ausgeübt werden kann, ist par excellence der koloniale Raum. Die Berichte von brutaler Herrschaft über die Körper aller Sklaven, von Männern wie Frauen oder Kindern, sind aus den Kolonien der unterschiedlichsten europäischen Mächte Legion.

Denn die Kolonialherren verfügten über die Körper ihrer Sklaven und insbesondere ihrer Sklavinnen frei nach Belieben. Noch ein Gilberto Freyre berichtete in der ersten Hälfte des 20. Jahrhunderts von manchen sexuellen Phantasien und Praktiken, denen die Sklavenhalter ihre Sklavinnen unterzogen und sie im 
Übrigen auch als willfährig gemachte Sexualobjekte benutzten. Dass hernach die weißen Frauen dieser schwarzen Herren die Körper dieser Sklavinnen verstümmelten, die zu Konkubinen ihrer Männer geworden waren, indem sie ihnen Gliedmaßen abschneiden ließen, schreckliche Wunden und Narben beibrachten oder anderweitig misshandelten, ${ }^{32}$ rundet unser Bild von der Unmenschlichkeit und Barbarei des europäischen Kolonialismus nur ab. Diesbezüglich nur von kontinuierlichen Misshandlungen zu sprechen, wäre ein Euphemismus.

Wie in der kolonialen Gesellschaft haben wir es bei de Sade mit den Exzessen und dem erotischen Überschuss einer patriarchalischen und phallogozentrischen Ständegesellschaft im Ancien Régime zu tun, die auf diesen Seiten deutlich in den Fokus rückt. Deren Gewaltexzesse und die verschiedenartigsten Unterwerfungspraktiken von Frauen werden bei Sade nur konsequent ins Bild gesetzt. Lust dürfen bei all diesen Praktiken die Frauen nur dann empfinden, wenn dies jene der beteiligten Männer noch zu steigern imstande ist. Hinter der sexuellen Ausbeutung steht die koloniale Ausbeutung - und umgekehrt.

All dies und noch viel mehr läuft im 18. Jahrhundert unter dem Stichwort des „Libertinage“; eine Wendung, die sich ebenso in den zahlreichen Bänden von Giacomo Casanovas Geschichte meines Lebens wie in den ausschweifenden Werken des Marquis de Sade findet. In diesem eleganten Ausdruck steckt noch das Freiheitslexem: Und in der Tat ist es die Freiheit der Sklavenbesitzer, die frei über die Körper ihrer Sklaven und Sklavinnen verfügen können. Freilich erfasst dies nur die eine Seite dieser Wortfügung, die selbstverständlich andererseits die Freidenker miteinschließt und auf eine politisch-emanzipatorische Agenda abzielt, welche wir ebenfalls nicht vergessen dürfen.

Doch herrscht der Libertin völlig frei über die Körper der ihm Untergebenen, der von ihm Beherrschten - wie ein Sklavenhalter über seine Sklaven. Und die Unterworfenen und Gefügig-Gemachten sind in der patriarchalischen Gesellschaft mit Vorliebe die Frauen, die in ihrer Rechtlosigkeit in der Gesellschaft des Ancien Régime gleichsam die Rolle der Sklaven einnehmen. dies lässt sich deutlich in der oben angeführten Passage aus Justine ou les malheurs de la vertu erkennen. Keine der verschiedensten Körperöffnungen dieser Liebesoder besser Sexsklavinnen ist dabei tabu, und alle können - wie in der obigen Szene - miteinander absichtsvoll kombiniert werden, frei nach dem Willen und den Gelüsten ihrer Herren. Aber lassen Sie uns an dieser Stelle einen Punkt ma-

32 Vgl. hierzu ausführlich Freyre, Gilberto: Casa-Grande \& Senzala. Formação da família brasileira sob o regime de economía patriarcal. 4a. edição, definitiva. Illustrações de Tomaz Santa Rosa. 2 Bde. Rio de Janeiro: Livrería José Olympio Editora 1943. 
chen! Denn ich denke, dass Sie die vielberufene Dialektik der Aufklärung vollauf erfasst und verstanden haben, wie selbst den Texten europäischer „philosophes“ zur „vie intime“ eine koloniale Semantik und Pragmatik unterliegt. Ohne diese koloniale Dialektik, die genderspezifisch offen zu Tage liegt, ist die Aufklärung zwischen zwei Welten nicht zu haben. 